Ageing, government budgets, retirement, and growth

Gonzalez Eiras, Martin; Niepelt, Dirk

Published in:

European Economic Review

Publication date:

2012

Citation for published version (APA):

Gonzalez Eiras, M., \& Niepelt, D. (2012). Ageing, government budgets, retirement, and growth. European Economic Review, 56(1), 97-115. 


\title{
Ageing, government budgets, retirement, and growth
}

\author{
Martín Gonzalez-Eiras ${ }^{\text {a,b }}$, Dirk Niepelt ${ }^{\text {c,d,e,* }}$ \\ a Universidad de San Andrés, Vito Dumas 284, B1644BID Victoria, Pcia. Buenos Aires, Argentina \\ b CONICET, Argentina \\ c Study Center Gerzensee, P.O. Box 21, CH-3115 Gerzensee, Switzerland \\ d University of Bern, Switzerland \\ e IIES, Stockholm University, Sweden
}

\section{A R T I C L E I N F O}

\section{Article history:}

Received 10 September 2010

Accepted 31 May 2011

Available online 14 June 2011

\section{JEL classification:}

E62

H5

J26

Keywords:

Ageing

Government budgets

Retirement

Growth

\begin{abstract}
A B S T R A C T
We analyze the short and long-run effects of demographic ageing - increased longevity and reduced fertility - on per-capita growth. The OLG model captures direct effects, working through adjustments in the savings rate, labor supply, and capital deepening, and indirect effects, working through changes of taxes, government spending components and the retirement age in politico-economic equilibrium. Growth is driven by capital accumulation and productivity increases fueled by public investment. The closed-form solutions of the model predict taxation and the retirement age in OECD economies to increase in response to demographic ageing and per-capita growth to accelerate. If the retirement age was held constant, the growth rate in politicoeconomic equilibrium would essentially remain unchanged, due to a surge of socialsecurity transfers and crowding out of public investment.
\end{abstract}

(c) 2011 Elsevier B.V. All rights reserved.

\section{Introduction}

The prospect of "graying" populations in many developed economies raises concerns about the sustainability of economic growth. According to these concerns, rising old-age dependency ratios translate into growing tax burdens while generous pension and health care benefits crowd out public investment spending for infrastructure or education, with negative effects for capital accumulation and productivity growth. However, the demographic transition has been ongoing for a while - developed economies have experienced a marked decrease in fertility and increase in longevity for several decades - without producing clear evidence that this transition has caused a fall in per-capita growth. Rather to the opposite, Barro and Sala-i-Martin (1995) find in growth regressions that both a decrease in the fertility rate and an increase in longevity are associated with higher growth rates. ${ }^{1}$

\footnotetext{
* Corresponding author. Tel.: +4131 7803101; fax: +41317803100.

E-mail addresses: mge@alum.mit.edu (M. Gonzalez-Eiras), dirk.niepelt@szgerzensee.ch (D. Niepelt).

${ }^{1}$ Falling fertility and increasing longevity can give rise to a temporary reduction in the (young age) dependency ratio, generating a "demographic dividend" of higher growth. In developed economies, this growth dividend is predicted to be exhausted around the year 2010 (e.g., Bloom et al., 2003 ). Also, Acemoglu and Johnson (2007) estimate the effect of life expectancy at birth on economic growth. They find no evidence of a positive effect.
} 


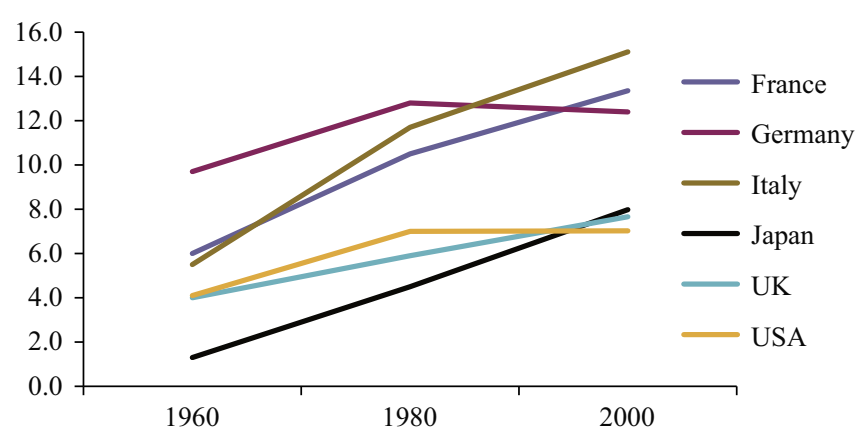

Fig. 1. Public expenditure on pensions, percent of GDP. Source: Tanzi and Schuknecht (2000), OECD.

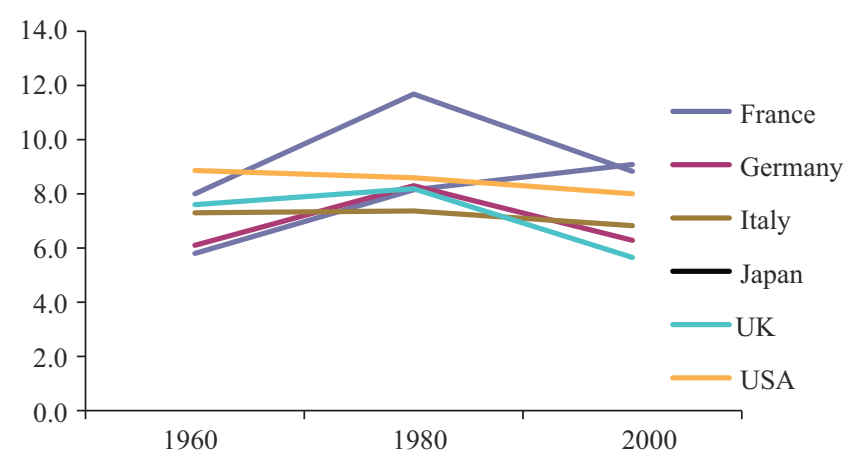

Fig. 2. Public expenditure on education and infrastructure investment, percent of GDP.

Source: Tanzi and Schuknecht (2000), OECD.

The evidence is similarly mixed as far as government budgets are concerned. While the GDP share of transfers to the elderly has increased, the share of public investment does not show a clear trend in most countries, see Figs. 1 and 2 . $^{2,3}$ Moreover, most developed countries have started to increase the retirement age or tighten the conditions for early retirement, reducing the pressure on social-security taxes.

To interpret this data and gauge likely future developments, we develop a tractable model to analyze the effects of demographic ageing on government budgets and per-capita growth. Building on a standard overlapping generations setup with private and public capital formation sustaining endogenous growth, our framework features two demographic driving forces - fertility and longevity - and a number of economic and political choices. In their role as economic agents, households in the model take prices, taxes, public investment, the retirement age and retirement benefits as given when choosing consumption, savings, and labor supply. In their role as voters, households choose among office motivated parties that offer policy platforms comprising labor income taxes, the expenditure shares for intergenerational transfers and public investment (reflecting spending components of central importance for developed economies), as well as the retirement age. The political process lacks commitment, and elections take place every period.

Policy choices in the model are of different concern to young and old voters: the exposure of households to labor income taxes changes over the life cycle; the old benefit from social-security transfers to their group but are hurt by an increase in the retirement age; and only the young benefit from the returns to public investment. When evaluating the policy platforms on offer in the political arena, voters therefore disagree as to which platform should ideally be implemented. We model the resolution of the ensuing conflict under the assumption of probabilistic voting, reflecting a small degree of randomness in voters' support for a party. In equilibrium, vote-seeking parties propose a policy platform maximizing average welfare of all voters, and changes in the economic or demographic environment give rise to a gradual adjustment of the policy instruments.

Policy choices do not only affect economic outcomes. Absent commitment, they also affect, indirectly, future policy decisions. In addition to the "economic" repercussions of their policy choices, voters internalize the "political" repercussions, reflected in the equilibrium relationship between future state variables and policy choices. We assume

\footnotetext{
${ }^{2}$ Data is taken from Tanzi and Schuknecht (2000) and OECD sources (Society at a Glance, 2009, old-age cash benefits, disability pensions and survivors' pensions; Economic Outlook, 2008, government fixed capital formation; Education At a Glance, 2008, direct public expenditure plus subsidies to households and other private entities). The GDP share of infrastructure investment has fallen in some countries, in contrast to the GDP share of education spending. In this paper, we do not analyze the composition of public investment.

${ }^{3}$ In cross-section data for the United States, the fraction of elderly residents in a district was negatively associated with education spending per child (Poterba, 1997).
} 
that only fundamental state variables enter this equilibrium relationship, excluding artificial state variables of the type sustaining trigger strategy equilibria. While we agree that the existence of intergenerational transfers or public investment may also owe to reputational arrangements, we focus on the Markov perfect equilibrium in order to identify the fundamental and robust forces that shape the size of these programs, and therefore growth. ${ }^{4}$

Under standard functional form assumptions, we characterize the politico-economic equilibrium in closed form. ${ }^{5}$ Changes in the demographic structure affect the equilibrium allocation both directly and indirectly, by inducing policy changes. The direct effect of changes in fertility and longevity works through modified private savings and labor-supply decisions which in equilibrium manifest themselves in faster capital accumulation. Indirectly, demographic ageing affects growth because it alters the relative political power of the old and the effect of later retirement on aggregate labor supply. At the same time, higher longevity increases the political support for public investment.

To quantify the equilibrium implications of demographic ageing, we analyze calibrated versions of the model representing a rich OECD economy, a rich European OECD economy, the United States, and Japan. For each of the countries and country blocks, the model predicts that the forecasted demographic changes give rise to a continued increase of the GDP share of social-security transfers, a slightly higher GDP share of public investment, a strong increase of the retirement age, and a rise in per-capita growth. In particular, annual per-capita growth is predicted to accelerate by approximately 35 basis points toward the end of the century.

Importantly, these findings hinge on the assumption that both fiscal policy and the retirement age are endogenous. With constant policy instruments, the growth rate would increase more strongly than in politico-economic equilibrium. With endogenous tax rates and budget shares but a fixed retirement age, the per-capita growth rate would essentially remain stuck at its current level in the medium run and increase only slightly in the long run, due to a surge of socialsecurity transfers and - most importantly - crowding out of public investment.

The central predictions of the model are robust to a variety of changes in the modeling assumptions. In particular, the results do not change if capital income taxes in addition to labor income taxes are introduced or if the balanced-budget assumption is relaxed. The results are also robust to replacing the endogenous-growth specification by one of exogenous growth. In the model, the political process does not internalize the long-term benefits of public investment because these occur beyond the lifetimes of even the youngest voters. As a consequence, the exact specification of productivity growth has no effect on the evolution of the policy instruments and the government budget shares in politico-economic equilibrium. Moreover, as we show, it does not have a strong effect on the evolution of output per capita in the medium run either.

While broadly consistent with the evidence, the model predictions contradict the common view among policy makers that the political process will implement measures to raise productivity in order to "outgrow" the burden imposed by demographic change. ${ }^{6}$ According to the model, demographic ageing indeed induces the political process to raise public investment in order to foster productivity growth. However, the main positive growth effects arise directly while the net effect of endogenous policy on growth is negative.

Our work relates to the literature analyzing the effects of government policy on growth, see Barro (1990), Jones et al. (1993) or Glomm and Ravikumar (1997) for a review. Our contribution relative to these papers lies in modeling the determinants of policy and linking fertility and longevity to growth. ${ }^{7}$ Galor and Weil (1999), Cervellati and Sunde (2005) and Soares (2005) analyze the growth effects of demographic change due to its impact on private savings and education decisions, and Hazan (2009) introduces private retirement decisions in a model of human capital accumulation. Our model complements these papers by modeling the role of policy and its determinants in politico-economic equilibrium, and by focusing on the ongoing demographic transition in developed economies rather than historical developments.

Our work also relates to politico-economic models of redistribution and growth. Alesina and Rodrik (1994), Persson and Tabellini (1994) and Krusell et al. (1997) argue that inequality depresses growth because anticipated redistributive taxation reduces the incentive to accumulate, or because higher inequality pushes the median voter's preferred level of public investment and taxes beyond the growth-maximizing level. Relative to these papers, we focus on inter- rather than intragenerational conflict, consider a larger set of policy instruments available to policy makers, and focus on the implications of fertility and longevity on growth. Our analysis therefore sheds light on the equilibrium size and composition of the government budget, and it emphasizes how demographic ageing affects both this composition and growth. ${ }^{8,9}$

Like Bellettini and Berti Ceroni (1999) and Rangel (2003), our paper analyzes the choice of productive versus redistributive public spending in an overlapping-generations model. In these papers, voters support public investment even if they do not directly benefit from it because a trigger strategy links investment spending to the provision of public pensions in the future. Our model adopts a different perspective. Rather than emphasizing complementarities between investment spending and transfer payments, it focuses on the conflict over the size of these two spending components, and

\footnotetext{
${ }^{4}$ For a discussion of Markov perfect equilibrium see Krusell et al. (1997).

5 Our functional form assumptions imply a minimal amount of strategic interaction between policy makers in different periods.

${ }^{6}$ See, for example, the discussions surrounding the European Union's "Lisbon Agenda."

7 Azzimonti et al. (2009) analyze capital formation by a benevolent government without commitment in a representative agent economy.

${ }^{8}$ Our work shares with Krusell et al. (1997) the restriction to Markov perfect equilibrium. Methodologically, it is related to Gonzalez-Eiras and Niepelt (2008)

${ }^{9}$ Glomm and Ravikumar (1992) and Perotti (1993) analyze distributive conflict in models with human capital accumulation. They focus on the political choice of public versus private education and the effect of distortive redistribution in the presence of borrowing constraints, respectively.
} 
how the resolution of this conflict is shaped by fertility and longevity. The model also differs from these papers in that it features political and economic choices, embedded in the standard growth model. This allows us to model the macroeconomic consequences of population ageing in a rich setting without having to sacrifice analytical tractability. Gradstein and Kaganovich (2004) argue that public investment might rise in response to increased longevity. Our model incorporates the mechanism underlying Gradstein and Kaganovich's (2004) argument. In addition, it features a role for fertility, the retirement age, a second government spending component that competes for funding, and - central to our analysis - growth effects of policy.

The remainder of the paper is structured as follows. Section 2 describes the model and characterizes the allocation conditional on policy. Section 3 solves for the politico-economic equilibrium and analyzes its properties. Section 4 contains the analysis of the short and long-run effects of demographic ageing on government budgets and macroeconomic outcomes, in particular the growth rate. Section 5 concludes.

\section{Economic environment}

We consider an economy inhabited by two-period lived overlapping generations: young households and old households. Young households in period $t$ supply labor, pay taxes, consume and save for retirement. They face idiosyncratic longevity risk: with probability $p_{t+1} \in(0,1]$, they survive to become old households in period $t+1$. Old households in turn consume the return on their savings, old-age benefits and the proceeds of their labor income in old age. The size of this labor income depends on the retirement age, $\varrho_{t}$, and the labor productivity of old relative to young workers, $\chi \geq 0 .{ }^{10}$ If $\varrho_{t}=0$ or $\chi=0$, the effective per-capita labor supply of old households equals zero. Old households die at the end of the period.

Each cohort consists of a continuum of homogeneous agents. The ratio of young to old households in period $t$ equals $v_{t} / p_{t}$, reflecting the gross rate of growth of the number of young households $v_{t}\left(v_{t}>0\right)$, fertility for short, and longevity $p_{t}{ }^{11}$ Both these demographic parameters follow deterministic processes. On a balanced-growth path, the survival probability is constant at value $p$ and the gross population growth rate is given by $v$. Savings of young households who die before reaching old age are distributed among their surviving peers, reflecting a perfect annuities market.

\subsection{Technology}

A continuum of competitive firms transforms capital and labor into output by means of a Cobb-Douglas technology. Capital depreciates after one period. The capital stock per young household, $k_{t}$, therefore corresponds to the per-capita savings of young households in the previous period, $s_{t-1}$, divided by the growth rate of the number of young workers, $v_{t}$. We normalize the period time endowment to unity and denote leisure consumption of the young and labor productivity by $x_{t}$ and $H_{t}$, respectively. Labor supply by an old worker in period $t$ equals $\varrho_{t}\left(1-x_{t}\right)$ reflecting the assumption that young and non-retired old households work the same number of hours. ${ }^{12}$ Labor supply per young household in period $t$ is then given by $\psi_{t}\left(\varrho_{t}\right)\left(1-x_{t}\right)$ with $\psi_{t}\left(\varrho_{t}\right) \equiv 1+\varrho_{t} \chi p_{t} / v_{t}$. Output per young household in period $t$ is given by

$$
B_{0} k_{t}^{\alpha}\left[H_{t} \psi_{t}\left(\varrho_{t}\right)\left(1-x_{t}\right)\right]^{1-\alpha},
$$

where $B_{0}>0$ and the capital share $\alpha \in(0,1)$.

Production factors are paid their marginal products, due to perfect competition. The wage per unit of time, $w_{t}$, and the gross return on physical capital, $R_{t}$, therefore satisfy

$$
\begin{aligned}
& w_{t}=(1-\alpha) B_{0} H_{t}^{1-\alpha} k_{t}^{\alpha}\left[\psi_{t}\left(\varrho_{t}\right)\left(1-x_{t}\right)\right]^{-\alpha}, \\
& R_{t}=\alpha B_{0} H_{t}^{1-\alpha} k_{t}^{\alpha-1}\left[\psi_{t}\left(\varrho_{t}\right)\left(1-x_{t}\right)\right]^{1-\alpha}=w_{t} \frac{\psi_{t}\left(\varrho_{t}\right)\left(1-x_{t}\right)}{k_{t}} \alpha^{\prime},
\end{aligned}
$$

with $\alpha^{\prime} \equiv \alpha /(1-\alpha)$. As a consequence of annuitization, the gross return on savings of a young household that survives to old age equals $\hat{R}_{t} \equiv R_{t} / p_{t}$.

Labor productivity $H_{t}$ reflects productive public investment during previous periods. ${ }^{13}$ More specifically, productivity growth is a function of public investment per young household,

$$
H_{t+1}=B_{1} H_{t}^{1-\delta} I_{t}^{\delta} \text {, }
$$

with $B_{1}>0, \delta \in(0,1)$ and $I_{t}$ denoting investment spending per young household. A specification of this type is standard in the literature. ${ }^{14}$

\footnotetext{
${ }^{10}$ To be precise, $\varrho_{t}$ equals the fraction of the period that an old household is required to work.

11 Net immigration also affects the rate of growth of the number of young households.

12 This assumption is not restrictive as changes in the hours worked by old households may be undone by changes in the retirement age.

13 Due to the Cobb-Douglas specification of the production function in the final good sector, $H_{t}$ can equivalently be interpreted as the total factor productivity. Since our objective is to analyze the link between changes in the size and composition of the population on the one hand and productivity growth on the other, we do not allow for scale effects as they are sometimes considered in endogenous-growth models.

${ }^{14}$ For example, Boldrin and Montes (2005) use the above specification (which is a special case of Rebelo, 1991), with $H_{t}$ interpreted as human capital and $I_{t}$ interpreted as public education.
} 


\subsection{Government}

The government taxes the labor income of young households in period $t$ at rate $\tau_{t}+\sigma_{t}$. Revenues fund transfers to retired old households - the component corresponding to $\tau_{t}$ - as well as public investment - the component corresponding to $\sigma_{t}$.

Denoting the total transfer to an old household by $b_{t}$, we have $\mathrm{i}^{15}$

$$
\begin{aligned}
& b_{t}=w_{t}\left(1-x_{t}\right) \tau_{t} v_{t} / p_{t}, \\
& I_{t}=w_{t}\left(1-x_{t}\right) \sigma_{t} .
\end{aligned}
$$

Public investment $I_{t}$, the transfer payment $b_{t}$ and the retirement age must be non-negative (we exclude lump-sum taxes). The policy instruments therefore have to satisfy ${ }^{16}$

$$
\tau_{t}, \sigma_{t}, \varrho_{t} \geq 0 \text { for all } t
$$

We denote a combination of the policy instruments in period $t$ by $\kappa_{t}, \kappa_{t} \equiv\left(\tau_{t}, \sigma_{t}, \varrho_{t}\right)$.

Note that we abstract from capital income taxes and impose a balanced-budget restriction. Both assumptions are without loss of generality. As discussed in the working paper version (Gonzalez-Eiras and Niepelt, 2007), a capital income tax rate would equal zero in equilibrium since, from the perspective of political decision makers who set policy instruments ex post, capital income taxes and old-age transfers are close substitutes. ${ }^{17}$ Similarly, old-age transfers and the repayment of government debt are close substitutes as well, rendering a balanced-budget restriction non-restrictive (see the discussion in Section 5).

\subsection{Preferences}

Young households value consumption during young age, $c_{1}$, and in old age, $c_{2}$, as well as leisure. Agents discount the future at factor $\beta \in(0,1)$. Due to the risk of death, the effective discount factor of young households equals $\beta p_{t+1}$. For analytical tractability, we assume that the period utility functions of consumption and leisure are logarithmic. Maximizing expected utility, a worker in period $t$ solves the following problem:

$$
\begin{array}{ll}
\max _{s_{t}, x_{t}} & \ln \left(c_{1, t}\right)+m \ln \left(x_{t}\right)+\beta p_{t+1}\left[\ln \left(c_{2, t+1}\right)+m \ln \left(1-\varrho_{t+1}\left(1-x_{t+1}\right)\right)\right] \\
\text { s.t. } & c_{1, t}=w_{t}\left(1-x_{t}\right)\left(1-\tau_{t}-\sigma_{t}\right)-s_{t}, \\
& c_{2, t+1}=s_{t} \hat{R}_{t+1}+w_{t+1}\left(1-x_{t+1}\right) \chi \varrho_{t+1}+b_{t+1},
\end{array}
$$

where $m \geq 0$ characterizes the preference for leisure. Note that the treatment of leisure is symmetric over the life cycle. Leisure consumption during old age equals the difference between the time endowment, 1, and the time spent working which reflects the intensive and extensive (retirement) margins of labor supply.

\subsection{Economic equilibrium}

The first-order conditions characterizing the households' savings and labor-supply decisions, respectively, are standard:

$$
\begin{aligned}
& \frac{1}{c_{1, t}}=\beta p_{t+1} \hat{R}_{t+1} \frac{1}{c_{2, t+1}}, \\
& \frac{m}{x_{t}}=w_{t}\left(1-\tau_{t}-\sigma_{t}\right) \frac{1}{c_{1, t}} .
\end{aligned}
$$

Substituting, the Euler equation characterizing the optimal savings choice of an individual household is given by

$$
\frac{s_{t} \hat{R}_{t+1}+w_{t+1}\left(1-x_{t+1}\right) \chi \varrho_{t+1}+b_{t+1}}{\beta p_{t+1} \hat{R}_{t+1}}=w_{t}\left(1-x_{t}\right)\left(1-\tau_{t}-\sigma_{t}\right)-s_{t} .
$$

Using $s_{t-1} R_{t} / v_{t}=w_{t} \psi_{t}\left(\varrho_{t}\right)\left(1-\chi_{t}\right) \alpha^{\prime}$, simplifying the left-hand side of the equation and setting individual and average savings equal to each other, we find the aggregate savings function

$$
s_{t}=z_{t+1}\left(\tau_{t+1}, \varrho_{t+1}\right) w_{t}\left(1-x_{t}\right)\left(1-\tau_{t}-\sigma_{t}\right)
$$

\footnotetext{
15 The transfer received while actually retired is $w_{t}\left(1-x_{t}\right) \tau_{t} v_{t} /\left(p_{t}\left(1-\varrho_{t}\right)\right)$. The total transfer received during old age is the product of this expression and $1-\varrho_{t}$. Alternative normalizations do not affect the results.

${ }^{16}$ We suppress the upper bound of unity on the retirement age since it will not be binding.

${ }^{17}$ In the presence of within-cohort heterogeneity, this need no longer be the case.
} 
where $z_{t+1}\left(\tau_{t+1}, \varrho_{t+1}\right)$ denotes the savings rate of young households in period $t$,

$$
z_{t+1}\left(\tau_{t+1}, \varrho_{t+1}\right) \equiv \frac{\alpha \beta}{\alpha\left(1+\beta p_{t+1}\right) / p_{t+1}+\frac{1-\alpha}{\left.\psi_{t+1} \varrho_{t+1}\right)}\left(\frac{\tau_{t+1}}{p_{t+1}}+\frac{\chi \varrho_{t+1}}{v_{t+1}}\right)} \geq 0 .
$$

Note that the savings rate in period $t$ depends on policy choices in period $t+1$. (If $\tau_{t+1}>0$ or $\chi \varrho_{t+1}>0$, old households receive retirement benefits or labor income in addition to the return on their savings. This renders the savings rate endogenous to policy, even with logarithmic preferences.) If these policy instruments themselves depend on aggregate savings, then the above relation characterizes savings only implicitly. We return to this point when discussing the objective function maximized in the political process.

Combining the first-order condition for leisure with the expression for $c_{1, t}$ yields

$$
x_{t}=\frac{m\left(1-z_{t+1}\left(\tau_{t+1}, \varrho_{t+1}\right)\right)}{1+m\left(1-z_{t+1}\left(\tau_{t+1}, \varrho_{t+1}\right)\right)} .
$$

Note that labor supply is independent of contemporaneous taxes as income and substitution effects cancel.

The endogenous state variables at time $t$ are $H_{t}$ and $k_{t}$. To simplify notation, we work with the state variables $H_{t}$ and $q_{t} \equiv H_{t}^{1-\alpha} k_{t}^{\alpha}$ instead. Let $\mathcal{L}_{t} \equiv B_{0}(1-\alpha) q_{t}\left(1-x_{t}\right)^{1-\alpha} \psi_{t}\left(\varrho_{t}\right)^{-\alpha}=w_{t}\left(1-x_{t}\right)$ denote labor income of a young household. Combining $k_{t}=s_{t-1} / v_{t}$ and the aggregate savings function with the dynamic budget constraint and the expressions for factor prices, the equilibrium allocation can recursively be expressed in terms of the following functions of state variables and policy instruments:

$$
\begin{aligned}
& k_{t+1}=\mathcal{L}_{t}\left(1-\tau_{t}-\sigma_{t}\right) z_{t+1}\left(\tau_{t+1}, \varrho_{t+1}\right) / v_{t+1}=s_{t} / v_{t+1}, \\
& c_{1, t}=\mathcal{L}_{t}\left(1-\tau_{t}-\sigma_{t}\right)\left(1-z_{t+1}\left(\tau_{t+1}, \varrho_{t+1}\right)\right) \text {, } \\
& c_{2, t}=\mathcal{L}_{t} v_{t}\left(\alpha^{\prime} \psi_{t}\left(\varrho_{t}\right) / p_{t}+\frac{\tau_{t}}{p_{t}}+\frac{\chi \varrho_{t}}{v_{t}}\right) \text {, } \\
& x_{t}=\frac{m\left(1-z_{t+1}\left(\tau_{t+1}, \varrho_{t+1}\right)\right)}{1+m\left(1-z_{t+1}\left(\tau_{t+1}, \varrho_{t+1}\right)\right)}, \\
& H_{t+1}=B_{1} H_{t}^{1-\delta}\left(\mathcal{L}_{t} \sigma_{t}\right)^{\delta} \text {, } \\
& q_{t+1}=\left(B_{1} H_{t}^{1-\delta}\left(\mathcal{L}_{t} \sigma_{t}\right)^{\delta}\right)^{1-\alpha}\left(\mathcal{L}_{t}\left(1-\tau_{t}-\sigma_{t}\right) z_{t+1}\left(\tau_{t+1}, \varrho_{t+1}\right) / v_{t+1}\right)^{\alpha} .
\end{aligned}
$$

Conditional on initial values for the two endogenous state variables, $\left(H_{0}, q_{0}\right)$, as well as a sequence of policy instruments, $\left\{\kappa_{t}\right\}_{t=0}^{\infty}$, conditions ( 3 ) fully characterize the equilibrium allocation. Taking logarithms, we can express the laws of motion of the two endogenous state variables as

$$
\left[\begin{array}{c}
\ln \left(H_{t+1}\right) \\
\ln \left(q_{t+1}\right)
\end{array}\right]=\underbrace{\left[\begin{array}{cc}
1-\delta & \delta \\
(1-\alpha)(1-\delta) & \alpha+\delta(1-\alpha)
\end{array}\right]}_{\equiv M}\left[\begin{array}{c}
\ln \left(H_{t}\right) \\
\ln \left(q_{t}\right)
\end{array}\right]+\underbrace{\left[\begin{array}{c}
\xi_{t}^{H}(\cdot) \\
\xi_{t}^{q}(\cdot)
\end{array}\right]}_{\equiv \xi_{t}}
$$

where the definitions of $\xi_{t}^{H}\left(\sigma_{t}, \varrho_{t}, \tau_{t+1}, \varrho_{t+1}\right)$ and $\xi_{t}^{q}\left(\tau_{t}, \sigma_{t}, \varrho_{t}, \tau_{t+1}, \varrho_{t+1}\right)$ follow from (3).

In the special case with inelastic labor supply, $m=0$, the equilibrium (3) maintain their validity and $x_{t}=0$.

\subsection{Balanced growth path}

Along a balanced-growth path, all tax rates and demographic variables are constant, implying that labor supply is timeinvariant as well. From (3), the growth rates of $k_{t}, s_{t}, c_{1, t}$, and $c_{2, t}$ then are equal to the growth rate of $q_{t}$. The laws of motion for the two endogenous state variables in (3) imply that, along the balanced-growth path, the gross growth rate of $H_{t}, \gamma_{H}$, equals the gross growth rate of $q_{t}$. For any time-invariant choice of tax rates, the last two equations in (3) therefore pin down the ratio $H_{t} / q_{t}$ on the corresponding balanced-growth path. Given this ratio, the same two conditions pin down $\gamma_{H}$ and thus, the balanced-growth rates of $q_{t}, k_{t}, s_{t}, c_{1, t}$, and $c_{2, t}$ :

$$
\begin{aligned}
\gamma_{H}= & \left(\left(B_{0} \psi(\varrho)^{-\alpha}(1-\alpha)(1-\chi)^{1-\alpha}\right)^{\delta} B_{1}^{1-\alpha}\left((1-\tau-\sigma) \frac{z(\tau, \varrho)}{v}\right)^{\alpha \delta} \sigma^{\delta(1-\alpha)}\right)^{1 / 1-\alpha(1-\delta)} \\
& \text { s.t. (2). }
\end{aligned}
$$

Gross population growth $v$ has a direct negative effect on per-capita growth because it reduces the capital stock per young household for a given savings rate (the effect captured by $v$ in the denominator), and a positive effect because it reduces total labor supply and increases wages given the stock of capital per young household (the effect captured by the term $\left.\psi(\varrho)^{-\alpha}\right)$. Longevity has a direct negative effect on growth by increasing the total labor supply and reducing wages given the stock of capital per young household (the effect captured by the term $\psi(\varrho)^{-\alpha}$, again). In addition, changes in fertility and longevity affect the savings rate and thus also labor supply of young households.

Income taxes depress growth because they lower disposable income of young households (the effect captured by the term $1-\tau-\sigma)$, as do retirement benefits because they lower the savings rate $(z(\cdot)$ is decreasing in $\tau)$. At the same time, 
public investment fosters productivity growth (the effect captured by $\sigma$ in the last term), in line with empirical evidence (e.g., Blankenau et al., 2007). Later retirement has a negative effect on growth. It lowers the wages of workers (the effect captured by $\left.\psi(\varrho)^{-\alpha}\right)$ and also decreases the savings rate.

In the following, we sometimes write the growth rate as $\gamma_{H}((p, v), \kappa(p, v))$ to indicate that demographic change affects growth both directly and indirectly, by altering the choice of policy instruments $\kappa_{t}$. Growth theory commonly analyzes the direct effect of demographic change on growth, $\partial \gamma_{H}((p, v), \kappa) / \partial(p, v)$, or the direct effect of policy on growth, $\partial \gamma_{H}((p, v), \kappa) / \partial \kappa$. Our objective is to analyze the combined direct and indirect effects of demographic change on growth, $\mathrm{d} \gamma_{H}((p, v), \kappa(p, v)) / \mathrm{d}(p, v)$. In Section 4 , we quantitatively assess these effects for advanced OECD economies.

Physical capital along the long-run growth path satisfies $k_{t+1}=\mathcal{L}_{t}(1-\tau-\sigma) z(\tau, \varrho) / v$. Since $k_{t}$ grows at the gross rate $\gamma_{H}$, it follows that

$$
\begin{aligned}
& \left(\frac{H_{t}}{k_{t}}\right)^{1-\alpha}=\frac{\gamma_{H} v}{B_{0} \psi(\varrho)^{-\alpha}(1-\alpha)(1-\chi)^{1-\alpha}(1-\tau-\sigma) z(\tau, \varrho)} \text { s.t. (2), } \\
& R=\frac{\alpha \psi(\varrho) \gamma_{H} v}{(1-\alpha)(1-\tau-\sigma) z(\tau, \varrho)} \text { s.t. (2). }
\end{aligned}
$$

\subsection{Exogenous growth specification}

The recent growth literature supports the notion that technology diffusion or trade linkages work toward an equalization of growth rates across regions and countries (see, e.g., Acemoglu, 2009, Chapter 18). In the context of our model, technology diffusion across countries can be modeled by positing that a country's growth rate of $H$ does not only depend on public investment in that country, but also on investment or productivity growth in other countries. For example, one may posit that

$$
H_{t+1}=B_{1} \bar{H}_{t}^{(1-\varepsilon)(1-\delta)} H_{t}^{\varepsilon(1-\delta)} I_{t}^{\delta},
$$

where $0 \leq \varepsilon<1$ and $\bar{H}_{t}$ denotes productivity in the rest of the world. (The model analyzed so far corresponds to the case $\varepsilon=1$.) To the extent that "foreign" productivity growth is exogenous, "domestic" long-term productivity growth is exogenous as well. In particular, domestic growth dynamics may then be modeled by a closed-economy specification,

$$
H_{t+1}=B_{1, t} H_{t}^{\varepsilon(1-\delta)} I_{t}^{\delta},
$$

where growth of $H, k$ and $q$ at rate $\gamma_{H}$ is sustained by exogenous growth of $B_{1, t}$ at the rate $\gamma_{B_{1}}=\gamma_{H}^{(1-\delta)(1-\varepsilon)}$.

In this exogenous-growth specification, the equations for $k_{t+1}, c_{1, t}$ and $c_{2, t}$ in (3) remain valid while the law of motion for the state variables in (4) changes to

$$
\left[\begin{array}{c}
\ln \left(H_{t+1}\right) \\
\ln \left(q_{t+1}\right)
\end{array}\right]=\left[\begin{array}{cc}
\varepsilon(1-\delta) & \delta \\
\varepsilon(1-\alpha)(1-\delta) & \alpha+\delta(1-\alpha)
\end{array}\right]\left[\begin{array}{c}
\ln \left(H_{t}\right) \\
\ln \left(q_{t}\right)
\end{array}\right]+\xi_{t},
$$

where $\xi_{t}$ differs from the corresponding expression in the endogenous-growth specification insofar as $B_{1, t}$ increases over time. The equilibrium expressions for $H_{t} / k_{t}$ and $R$ given above still apply.

\section{Politico-economic equilibrium}

We assume that young and old households vote on candidates whose electoral platforms specify values for the policy instruments, $\kappa_{t}$. Voters do not only support a candidate for her policy platform, but also for other characteristics ("ideology") that are orthogonal to the fundamental policy dimensions of interest. These characteristics are permanent and cannot be credibly altered in the course of electoral competition. Moreover, their valuation differs across voters (even if voters agree about the preferred policy platform) and is subject to random aggregate shocks, realized after candidates have chosen their platforms. This "probabilistic-voting" setup renders the probability of winning a voter's support a continuous function of the competing policy platforms, implying that equilibrium policy platforms smoothly respond to changes in the demographic structure. This stands in contrast to the "median-voter" setup where, in a model with only a few generations, a small change in the demographic structure has large effects on policy outcomes if it alters the cohort the median voter is associated with.

In the Nash equilibrium of the probabilistic-voting game with two candidates choosing platforms to maximize their expected vote shares, both candidates propose the same policy platform. ${ }^{18}$ This platform maximizes a convex combination of the objective functions of all groups of voters, where the weights reflect the groups' size and sensitivity of voting behavior to policy changes. Those groups that care the most about policy platforms rather than other candidate characteristics are the most likely to shift their support from one candidate to the other in response to small changes

\footnotetext{
18 See Lindbeck and Weibull (1987) and Persson and Tabellini (2000) for discussions of the probabilistic-voting setup.
} 
in the proposed platforms. In equilibrium, such groups of "swing voters" thus gain in political influence and tilt policy in their own favor. If all voters are equally responsive to changes in the policy platforms, electoral competition implements the utilitarian optimum with respect to voters.

Owing to political competition at the beginning of each period, policy makers cannot commit to future policy platforms. Voters therefore have to form expectations about the effect of current policy choices on future policy outcomes. Under the Markov assumption, future leisure and policy choices are functions of the fundamental state variables only, $x_{t+1}=\tilde{x}_{t+1}\left(H_{t+1}, q_{t+1}\right)$ and $\kappa_{t+1}=\tilde{\kappa}_{t+1}\left(H_{t+1}, q_{t+1}\right)$. (The state variables include demographic variables, thus the time indices of the policy functions.) If the policy functions are independent of $(H, q), \kappa_{t+1}=\tilde{\kappa}_{t+1}$, then (2) implies that the leisure function is independent of $(H, q)$ as well, $x_{t+1}=\tilde{x}_{t+1}$, and both the aggregate savings function and the economic equilibrium (3) apply (recall the discussion of the aggregate savings function in Section 2.4). In the following, we conjecture that the policy functions indeed are independent of $(H, q)$. We derive the equilibrium choice of policy instruments under this conjecture and show that this choice does not depend on $(H, q)$, thereby verifying the conjecture

The political objective function, $W_{t}(\cdot)$, depends on the endogenous state variables (as well as the exogenous ones, thus the time index), the contemporaneous policy instruments, and the anticipated values of policy instruments and leisure in the following period. Letting $\omega$ denote the per-capita political influence of old relative to young households, we define

$$
\begin{aligned}
& \begin{aligned}
W_{t}\left(H_{t}, q_{t}, \kappa_{t} ; \tilde{\kappa}_{t+1}, \tilde{x}_{t+1}\right) \equiv & \omega p_{t}\left\{\ln \left(c_{2, t}\right)+m \ln \left(1-\varrho_{t}\left(1-x_{t}\right)\right)\right\}+v_{t}\left\{\ln \left(c_{1, t}\right)+m \ln \left(x_{t}\right)\right. \\
& \left.+\beta p_{t+1}\left[\ln \left(c_{2, t+1}\right)+m \ln \left(1-\varrho_{t+1}\left(1-x_{t+1}\right)\right)\right]\right\}
\end{aligned} \\
& \text { s.t. (3), } \kappa_{t+1}=\tilde{\kappa}_{t+1}, x_{t+1}=\tilde{x}_{t+1} .
\end{aligned}
$$

The program characterizing equilibrium policy choices in period $t$ is given by

$$
\max _{\kappa_{t}} W_{t}\left(H_{t}, q_{t}, \kappa_{t} ; \tilde{\kappa}_{t+1}, \tilde{x}_{t+1}\right) \text { s.t. (1), } H_{t}, q_{t} \text { given. }
$$

Political equilibrium requires that for any combination of state variables $\left(H_{t}, q_{t}\right)$, the $\kappa_{t}$ solving this program is given by $\tilde{\kappa}_{t}$. Using the equilibrium expressions for consumption from (3), the objective function can be expressed as

$$
\begin{aligned}
W_{t}(\cdot)= & \omega p_{t}\left\{\ln \left[\psi_{t}\left(\varrho_{t}\right)^{-\alpha}\left(\alpha^{\prime} \psi_{t}\left(\varrho_{t}\right) / p_{t}+\frac{\tau_{t}}{p_{t}}+\frac{\chi \varrho_{t}}{v_{t}}\right)\right]+m \ln \left(1-\varrho_{t}\left(1-x_{t}\right)\right)\right\}+v_{t}\left\{\ln \left[\psi_{t}\left(\varrho_{t}\right)^{-\alpha}\left(1-\tau_{t}-\sigma_{t}\right)\right]\right. \\
& \left.+\beta p_{t+1} \ln \left[\left(\psi_{t}\left(\varrho_{t}\right)^{-\alpha}\right)^{\delta(1-\alpha)+\alpha}\left(1-\tau_{t}-\sigma_{t}\right)^{\alpha} \sigma_{t}^{\delta(1-\alpha)}\right]\right\}+ \text { t.i.p. s.t. (2), }
\end{aligned}
$$

where t.i.p. denotes terms that are unaffected by contemporaneous policy choices (under the conjecture), due to the logarithmic preference assumption. In particular, t.i.p. includes $H_{t}$ and $q_{t}$ and, with an exogenous-growth specification, the parameter $\varepsilon$ determining the strength of the intertemporal spillover from $H$. Since the contemporaneous policy instruments do not interact with the state variables $H_{t}$ or $q_{t}$, the equilibrium policy functions are independent of these state variables, confirming the initial conjecture. ${ }^{19}$ Similarly, since in the case with an exogenous-growth specification the parameter $\varepsilon$ does not interact with the policy instruments, the equilibrium policy choices in the endogenous and exogenous-growth specifications of the model coincide. This is a reflection of the fact that the political process does not internalize the long-term benefits of public investment because these occur beyond the lifetimes of even the youngest voters.

Letting $\Delta_{t+1} \equiv 1+\beta p_{t+1}(\alpha+\delta(1-\alpha))$ denote the semi-elasticity of young households' utility with respect to labor income, the first-order conditions with respect to $\tau_{t}, \sigma_{t}$ and $\varrho_{t}$, respectively, read

$$
\begin{aligned}
& \frac{\omega p_{t}}{v_{t}} \frac{\frac{1}{p_{t}}}{\alpha^{\prime} \psi_{t}\left(\varrho_{t}\right) / p_{t}+\frac{\tau_{t}}{p_{t}}+\frac{\chi \varrho_{t}}{v_{t}}}+\lambda^{\tau}=\frac{1+\alpha \beta p_{t+1}}{1-\tau_{t}-\sigma_{t}}, \\
& \frac{\delta(1-\alpha) \beta p_{t+1}}{\sigma_{t}}+\lambda^{\sigma}=\frac{1+\alpha \beta p_{t+1}}{1-\tau_{t}-\sigma_{t}}, \\
& \frac{\omega p_{t}}{v_{t}}\left(\frac{\alpha^{\prime} \psi_{t}^{\prime}\left(\varrho_{t}\right) / p_{t}+\chi / v_{t}}{\alpha^{\prime} \psi_{t}\left(\varrho_{t}\right) / p_{t}+\frac{\tau_{t}}{p_{t}}+\frac{\chi \varrho_{t}}{v_{t}}}-\frac{m\left(1-x_{t}\right)}{\left(1-\varrho_{t}\left(1-\chi_{t}\right)\right)}\right)+\lambda^{\varrho}=\frac{\alpha \psi_{t}^{\prime}\left(\varrho_{t}\right)}{\psi_{t}\left(\varrho_{t}\right)}\left(\frac{\omega p_{t}}{v_{t}}+\Delta_{t+1}\right),
\end{aligned}
$$

where the $\lambda$ s denote multipliers associated with the non-negativity constraints on the policy instruments.

If the tax rates $\tau_{t}$ and $\sigma_{t}$ are interior (as is the case in the data and in the simulations we conduct later) and $\varrho_{t}$ is in a corner then we can solve the former two first-order conditions for

$$
\tau_{t}=\frac{\frac{\omega p_{t}}{v_{t}}-\alpha^{\prime} \Delta_{t+1}}{\frac{\omega p_{t}}{v_{t}}+\Delta_{t+1}},
$$

${ }^{19}$ In related work, we analyze the sensitivity of a parallel result to changes in functional form assumptions (Gonzalez-Eiras and Niepelt, 2005). We find that, in the case of generalized CRRA preferences, state variables and policy instruments do interact. However, the quantitative implications for equilibrium policies are negligible. 


$$
\sigma_{t}=\beta \delta p_{t+1} \frac{1}{\frac{\omega p_{t}}{v_{t}}+\Delta_{t+1}},
$$

implying that tax rates in period $t$ depend on demographics in periods $t$ and $t+1$.

If the three instruments have an interior solution, solving the first-order conditions yields

$$
\begin{aligned}
\tau_{t} & =\frac{(1-\alpha)\left(\frac{\omega p_{t}}{v_{t}}+\Delta_{t+1}\right)+\frac{\omega p_{t}}{v_{t}} m-\Delta_{t+1}\left(1+\frac{\chi p_{t}}{v_{t}\left(1-x_{t}\right)}\right)}{(1-\alpha)\left(\frac{\omega p_{t}}{v_{t}}+\Delta_{t+1}\right)+\frac{\omega p_{t}}{v_{t}} m} \\
\sigma_{t} & =\beta \delta p_{t+1} \frac{(1-\alpha)\left(1+\frac{\chi p_{t}}{v_{t}\left(1-x_{t}\right)}\right)}{(1-\alpha)\left(\frac{\omega p_{t}}{v_{t}}+\Delta_{t+1}\right)+\frac{\omega p_{t}}{v_{t}} m} \\
\varrho_{t} & =\frac{(1-\alpha)\left(\frac{\omega p_{t}}{v_{t}}+\Delta_{t+1}\right) /\left(1-x_{t}\right)-\frac{\omega}{\chi} m}{(1-\alpha)\left(\frac{\omega p_{t}}{v_{t}}+\Delta_{t+1}\right)+\frac{\omega p_{t}}{v_{t}} m}
\end{aligned}
$$

Since $x_{t}$ is a function of future policy choices (see (2)) it appears that, in this case, the policy instruments effectively depend on current and all future demographic shocks. This is not the case, however, because the combination of policy instruments entering into the expression for labor supply ${ }^{20}$ in period $t$ does not depend on $1-x_{t+1}$ but only on parameters and demographic shocks in periods $t+1$ and $t+2$ :

$$
1-x_{t}=1-\frac{m}{1+m+\beta p_{t+1}\left(1+\frac{\Delta_{t+2} v_{t+1}}{\omega p_{t+1}}\right) \alpha} .
$$

Accordingly, the equilibrium policy choices $\kappa_{t}$ only depend on parameters and demographic shocks in periods $t$ through $t+2$.

Demographic change affects the policy instruments through several channels. (Unless otherwise noted, the comparative statics results for $\tau_{t}$ and $\sigma_{t}$ hold even if $\varrho_{t}$ is in a corner or fixed.) First, by altering the relative political power of the old in the current period, $\omega p_{t} / v_{t}$. Higher relative political power of the old (reflecting a higher number of old relative to young households due to lower fertility or higher longevity in the previous period) raises $\tau_{t}$ and lowers $\sigma_{t}$ and $\varrho_{t}{ }^{21}$ Intuitively, more powerful elderly voters secure higher intergenerational transfers and earlier retirement. Because taxes are distorting, funding for other government outlays is reduced.

Second, demographic change affects the policy instruments by altering the effect of later retirement on aggregate labor supply, $\chi p_{t} / v_{t}$. A stronger such effect (reflecting a higher number of old relative to young households, again) reduces $\tau_{t}$ and increases $\sigma_{t}$ and $\varrho_{t}$. Intuitively, a higher number of old relative to young households strengthens the extent to which an increase in the retirement age translates into available resources. The additional resources generated due to later retirement reduce the need for intergenerational transfers and limit tax distortions. This allows to increase funding for public investment. The combined effect of the first two channels (reflecting the number of old relative to young households in the current period) is to raise $\tau_{t}$ and $\varrho_{t}$ and lower $\sigma_{t}$ in response to demographic ageing. That is, the retirement age rises during the demographic transition although the relative political power of the old increases when society ages.

Third, demographic change affects the policy instruments by altering the longevity of young households, $p_{t+1}$, and thus, the weight the political process attaches to the future (see also Gradstein and Kaganovich, 2004). With a higher such weight, public investment becomes easier to sustain politically. As a consequence, an increase in longevity reduces $\tau_{t}$ but increases $\sigma_{t}$ and $\varrho_{t}$.

Finally, with an interior retirement age, future demographic change affects the policy instruments by altering policy choices in the subsequent period and thus contemporaneous labor supply. In particular, increases in $p_{t+1}, v_{t+1}$ and $p_{t+2}$ all raise $1-x_{t} \cdot{ }^{22}$ Higher contemporaneous labor supply in turn increases $\tau_{t}$ and reduces $\sigma_{t}$ and $\varrho_{t}$. Intuitively, higher contemporaneous labor supply raises the disutility of later retirement for the old; as a consequence, the retirement age is reduced, transfers increased, and public investment falls.

The comparative statics results working through the first channel correspond with conventional wisdom. Often overlooked are the consequences of the other channels, as well as the fact that their interaction generates non-monotone dynamics. For example, a permanent shock to longevity may give rise to a fall in the tax rate $\tau$ in the period preceding the

${ }^{20}$ This combination is given by

$$
\frac{1-\alpha}{\psi_{t+1}\left(\varrho_{t+1}\right)}\left(\frac{\tau_{t+1}}{p_{t+1}}+\frac{\chi \varrho_{t+1}}{v_{t+1}}\right),
$$

see Eq. (2).

${ }^{21}$ We interpret the ratio $\omega / \chi$ as $\omega p_{t} / v_{t} / \chi p_{t} / v_{t}$.

${ }^{22}$ Recall from (2) that $x_{t}=m /\left(1+m+\beta p_{t+1}\right)$ if $\tau_{t+1}=\varrho_{t+1}=0$. That is, absent transfer or labor income in old age, higher longevity increases labor supply because it raises the savings rate of young households. The additional term in the equilibrium expression for labor supply, $\left(1+\Delta_{t+2} v_{t+1} / \omega p_{t+1}\right) \alpha$, arises because $\tau_{t+1}$ and $\varrho_{t+1}$ differ from zero in politico-economic equilibrium, with the equilibrium size of these instruments determined by $\Delta_{t+2}$ and $\omega p_{t+1} / v_{t+1}$ (see the discussion above). 
shock (where longevity fosters the incentive to invest) followed by a recovery thereafter (where it strengthens the political power of the old). In response to the same shock, the tax rate $\sigma$ may display the opposite dynamics while the retirement age rises both in the short and the long run. Before the background of these non-monotone dynamics, data about the shortrun evolution of government budget shares cannot easily be extrapolated to predict the direction of long-run change in these shares. $^{23}$

The equilibrium policy functions $\kappa_{t}$ are unique in the limit of the finite horizon economy. To see this, consider the final period $T$ and note that labor supply is inelastic in this final period (from (2)). The political objective function in period $T$ therefore depends on the consumption of young and old households,

$$
c_{1, T}=\mathcal{L}_{T}\left(1-\tau_{T}\right) \quad \text { and } \quad c_{2, T}=\mathcal{L}_{T} v_{T}\left(\frac{\left(\alpha^{\prime}+1\right) \psi_{T}\left(\varrho_{T}\right)+\tau_{T}-1}{p_{T}}\right),
$$

respectively. Note that $\sigma_{T}=0$ since there is no benefit of public investment in the final period. Differentiating the political objective function in period $T$ with respect to $\tau_{T}$ and $\varrho_{T}$ yields two equations in the policy instruments that are independent of $\left(H_{T}, q_{T}\right)$. This implies that $\kappa_{T}$ is not a function of $\left(H_{T}, q_{T}\right)$. Moving to period $T-1$, the forgoing analysis shows that the policy functions $\kappa_{T-1}$ are independent of $\left(H_{T-1}, q_{T-1}\right)$ as well, and given by the equilibrium expressions reported earlier. The result then follows by induction.

In Appendix A, we derive as a criterion for production efficiency along a balanced-growth path the requirement that

$$
1 \geq \alpha^{\prime} \frac{I}{S}>\delta
$$

If either of the two inequalities is violated then a reallocation of investment spending between $I$ and $s$ may weakly increase output in all future periods, and strictly in some (see Cass, 1972). In particular, if the left inequality is violated, the economy accumulates too much $H$ and if the right inequality is violated, the economy accumulates too much $k$. As shown in Appendix A, the economy necessarily over accumulates $k$ relative to $H$ in politico-economic equilibrium. As a consequence, the allocation in politico-economic equilibrium necessarily differs from the allocation supported by any Ramsey policy. ${ }^{24}$

\section{Quantitative implications of demographic ageing}

Based on the analytical results derived earlier, we compute quantitative predictions for a synthetic "rich OECD economy," representing the population weighted average of Australia, Canada, Denmark, France, Germany, Italy, Japan, New Zealand, Sweden, the United Kingdom and the United States; a synthetic "rich European OECD economy," representing the population weighted average of the European countries in the above list; the United States; and Japan. We take one period in the model to correspond to 30 years in the data. Accordingly, we compute three sequences of model predictions with a period length of 30 years each. In the first sequence, the periods correspond to the years 1970,2000 , $2030, \ldots$; in the second sequence, to the years $1980,2010,2040, \ldots$; and in the third sequence, to the years 1990,2020 , $2050, \ldots$. When reporting time series predictions, we list the three sequences in a single time series.

We use the 30-year population growth rate as a measure of $v_{t}$, the number of young households in period $t$ relative to the number in the preceding period. For $p_{t}$, the number of old households in period $t$ relative to the number of young households in the preceding period, we use estimates for life expectancy at age 65 divided by 30 years. ${ }^{25}$ Figs. 3 and 4 plot the demographic series underlying the model predictions.

We set $\alpha$ to 0.3 , a standard value in the literature, normalize $B_{0}$ to unity, and let $\chi=1.135$, based on estimates of labor productivity over the life cycle in Heathcote et al. (2010). ${ }^{26}$ To calibrate $\beta, \delta, \omega, B_{1}$ and $m$, we impose model restrictions. First, we fix the GDP-shares of transfers and public investment in the year $2000,(1-\alpha) \tau_{2000}$ and $(1-\alpha) \sigma_{2000}$, respectively, at the values 0.0796 and 0.0727 , the corresponding averages in the rich OECD economy. ${ }^{27}$ Second, we fix the balanced-

${ }^{23}$ The comparative statics with respect to the structural parameters of the model are intuitive. For example, an increase in the preference for leisure, $m$, raises the marginal cost of working for the old and induces the political process to reduce the retirement age and shift government spending from investment to social-security benefits. The effect working through changes in labor supply reinforces this adjustment. If the retirement age is fixed, changes in $m$ do not affect the two tax rates. An increase in the elasticity of productivity growth to public investment, $\delta$, leads to a reduction of $\tau_{t}$ and an increase in $\sigma_{t}$ and $\varrho_{t}$.

${ }^{24}$ With exogenous growth $(\varepsilon<1)$, the production inefficiency result remains valid, see Appendix A. The political process does not internalize the dynamic externality from current to future $H$, in contrast to a Ramsey planner. As a consequence, the strength of this dynamic externality is irrelevant for the equilibrium $\kappa_{t}$.

25 Demographic data from the year 1950 onward is taken from Population Division of the Department of Economic and Social Affairs of the United Nations Secretariat (2005, 2007): World Population Prospects, New York. Population data for the year 1940 is taken from http://www.populstat.info. Data about life expectancy at age 65 is available up to the year 2000. Data for 2010-2050 is extrapolated from data about life expectancy at birth Demographic data for the year 2060 and later is extrapolated under the assumption that $p$ and $v$ converge to unity in the long run.

26 We fit a polynomial to Heathcote et al. (2010) estimates for the United States and compute the average values before and after age 65.

27 We proxy the former by the GDP-share of old-age and survivors pensions and the latter by the GDP-share of government fixed capital formation and (other) government expenditures for education (all levels of government). Data is taken from OECD sources. (Due to data limitations, the components underlying the historical shares reported in the Introduction differ slightly from the ones we choose for the calibration. In particular, the historical pension-share series contains disability benefits and the historical investment-share series may be slightly biased due to double counting.) 


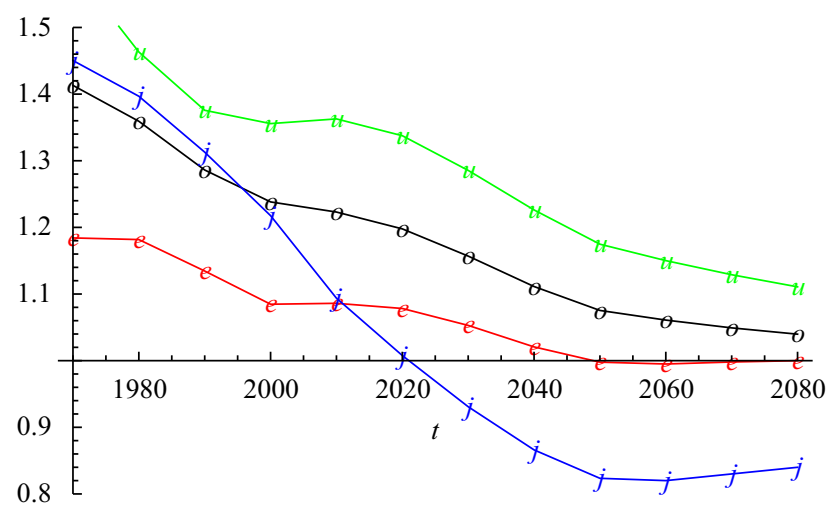

Fig. 3. $v_{t}$ for the rich OECD economy (black, "o"), the rich European OECD economy (red, "e"), the United States (green, "u"), and Japan (blue, "j"). (For interpretation of the references to color in this figure legend, the reader is referred to the web version of this article.)

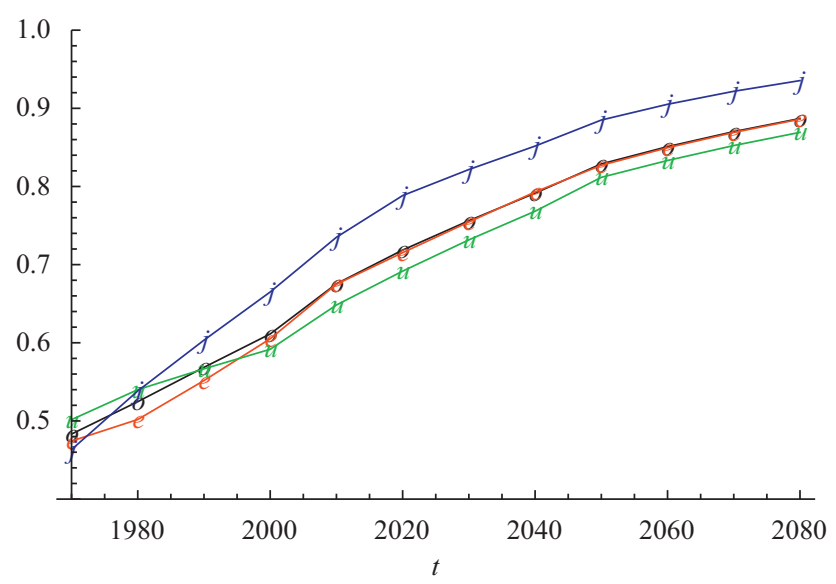

Fig. 4. $p_{t}$ for the rich OECD economy (black, "o"), the rich European OECD economy (red, "e"), the United States (green, "u"), and Japan (blue, “j”). (For interpretation of the references to color in this figure legend, the reader is referred to the web version of this article.)

growth-path growth rate and interest rate when evaluated at the year-2000 demographics at the observed values in the rich OECD economy. ${ }^{28}$ Finally, we fix the labor supply of a young household in the year 2000 at $1 / 3$. These restrictions imply $\beta=0.7226$ ( 0.9892 on an annual basis), $\delta=0.4039, \omega=1.8256, B_{1}=10.7738$ and $m=2.7011$.

Figs. 5-9 display the predicted policy responses to demographic change in the rich OECD economy, the rich European OECD economy, the United States, and Japan. All simulations are based on the calibration described above and differ only with respect to the demographic series fed into the model. As a consequence, the actual budget shares in the year 2000 are exactly matched in the case of the rich OECD economy.

According to the model predictions displayed in Fig. 5, $\tau_{t}$ more than doubles in the rich OECD economy between the years 1970 and 2000, flattening out thereafter and increasing further by approximately three percentage points up to the year 2080. Tax rate $\sigma_{t}$ increases much slower, rising by slightly more than two percentage points between the years 1970 and 2080. In sample, these predictions are broadly consistent with the evidence on public investment and intergenerational transfers (see Figs. 1 and 2) although the model over predicts the speed with which social-security taxes increase. Retirement age $\varrho_{t}$ in the model rises by an amount corresponding to roughly 6 years between 2000 and 2080 , to be compared with an increase in life expectancy at age 65 of more than 8 years. Labor supply of young households (not displayed) rises by more than $1 \%$ between 1970 and 2000 and by another percent between 2000 and 2080 . In contrast with the savings rate of young households, the national savings rate (not displayed) is predicted to fall from more than $7 \%$ in 1970 to roughly $6 \%$ in 2010 and roughly $4 \%$ in 2080 , due to the increased fraction of the elderly who are dissaving.

If the retirement age was not allowed to rise beyond its level in the year 2000, the tax rate $\tau_{t}$ would increase steeply and $\sigma_{t}$ would decline, see Fig. 6. Intuitively, with a capped $\varrho_{t}$ the growing number of non-working old relative to young households would require increasingly high social-security contributions per young household and the induced rise in $\tau_{t}$ would render taxation more costly, triggering a fall in the tax rate $\sigma_{t}$ and crowding out of government investment.

\footnotetext{
${ }^{28}$ We calibrate $\gamma_{H}$ based on the average annual multifactor productivity growth rate of the rich OECD economy between the years 1985 and 2005 , 1.0113 (OECD sources), and $R$ based on Gonzalez-Eiras and Niepelt (2008) estimate of the annual gross interest rate in the United States, 1.0483.
} 


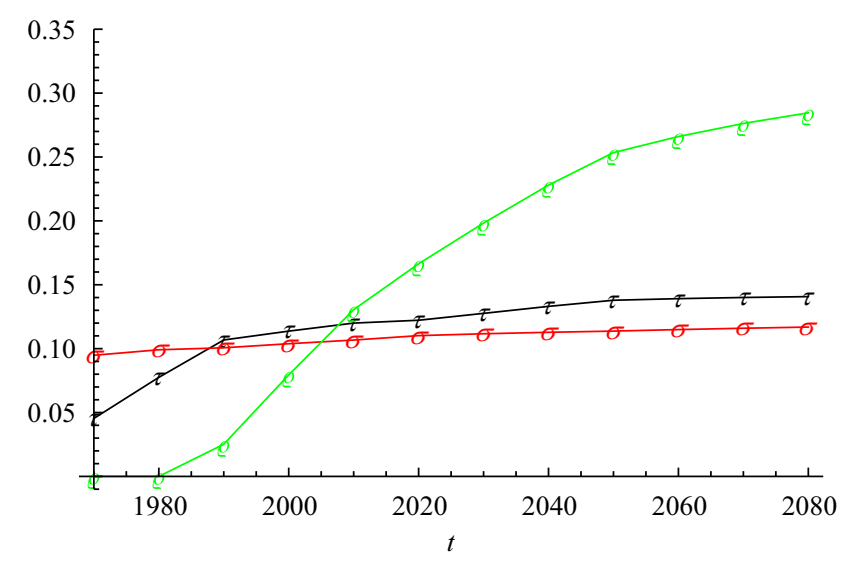

Fig. 5. Predicted policies for the rich OECD economy: $\tau_{t}$ (black), $\sigma_{t}$ (red), $\varrho_{t}$ (green). (For interpretation of the references to color in this figure legend, the reader is referred to the web version of this article.)

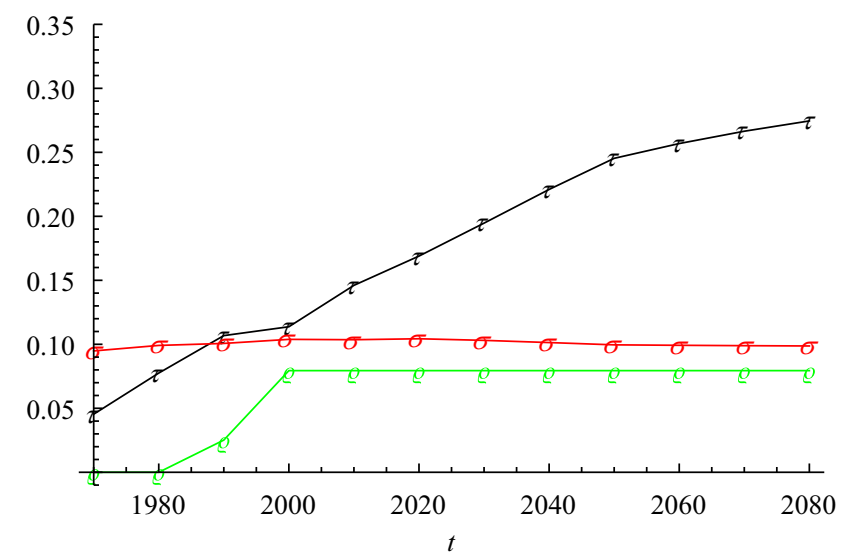

Fig. 6. Predicted policies for the rich OECD economy if $\varrho_{t}$ is capped at its year-2000 value: $\tau_{t}$ (black), $\sigma_{t}$ (red), $\varrho_{t}$ (green). (For interpretation of the references to color in this figure legend, the reader is referred to the web version of this article.)

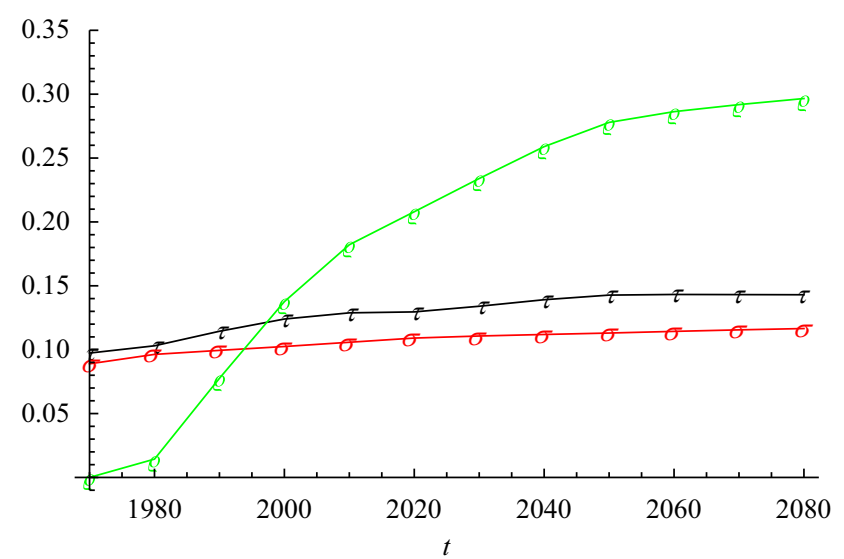

Fig. 7. Predicted policies for the rich European OECD economy: $\tau_{t}$ (black), $\sigma_{t}$ (red), $\varrho_{t}$ (green). (For interpretation of the references to color in this figure legend, the reader is referred to the web version of this article.)

Interestingly, this scenario closely corresponds with fears voiced in the policy debate. While the model encompasses the mechanisms underlying such fears, it predicts a different resolution of intergenerational conflict because of adjustments along the retirement margin.

Returning to the scenario where all three policy instruments are free to adjust, the predicted policy responses in the rich European OECD economy, the United States and Japan are similar as far as the public investment share is concerned, 


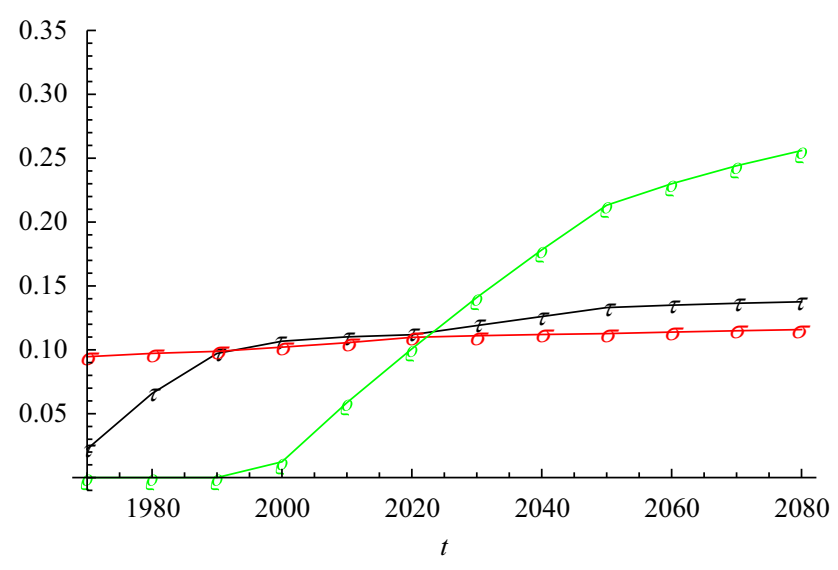

Fig. 8. Predicted policies for the United States: $\tau_{t}$ (black), $\sigma_{t}$ (red), $\varrho_{t}$ (green). (For interpretation of the references to color in this figure legend, the reader is referred to the web version of this article.)

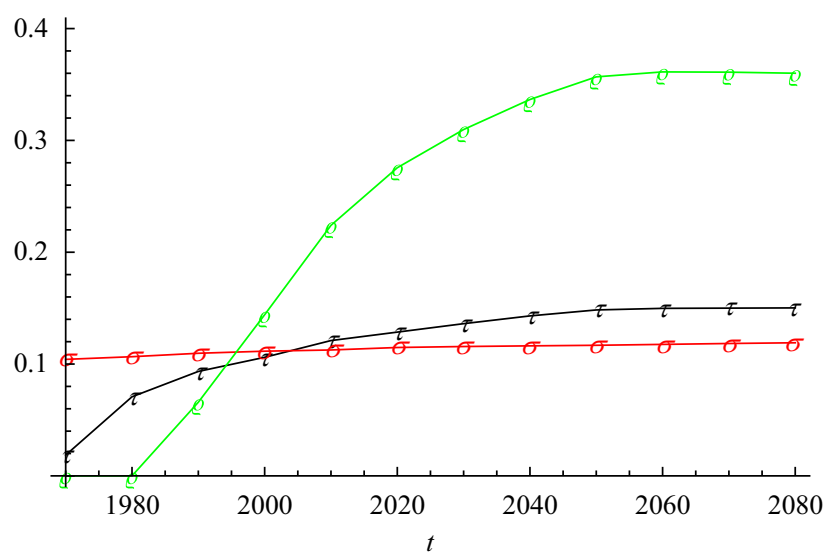

Fig. 9. Predicted policies for Japan: $\tau_{t}$ (black), $\sigma_{t}$ (red), $\varrho_{t}$ (green). (For interpretation of the references to color in this figure legend, the reader is referred to the web version of this article.)

see Figs. 7-9. The main differences between the three economies concern the budget share for social-security transfers on the one hand and the retirement age on the other: the social-security budget share in the United States and Japan starts out from a lower level than in the rich European OECD economy but catches up during the early years of the simulation; and the retirement age increases earlier in the rich European OECD economy and Japan than in the United States.

In broad terms, these predictions about the relative performance of the three countries and country blocks are consistent with the evidence. In particular, the model predicts the GDP-share of social-security transfers in the year 2000, $(1-\alpha) \tau_{2000}$, to be highest in the rich European OECD economy (nearly 9\%), followed by Japan and the United States (more than $7 \%$ ). In the data, the corresponding shares equal roughly $10 \%, 8 \%$, and $6 \%$, respectively. Similarly, the model correctly predicts that the GDP-share of public investment, $(1-\alpha) \sigma_{2000}$, is higher in Japan than in the United States and the rich European OECD economy: The model predicts GDP-shares of nearly $8 \%$ for Japan and more than $7 \%$ for the United States and the rich European OECD economy, in line with the data. The model also performs well in predicting a sharp increase of retirement age in Japan around the year 1990 and a smoother and later response in the United States. ${ }^{29}$ It performs less satisfactory in predicting a robust increase of retirement age in the rich European OECD economy by the year $1990 .^{30}$

Fig. 10 displays the predicted annual per-capita output growth rates for the four countries and country blocks under consideration. These growth rates are reported as deviations from the balanced-growth rates subject to the year-2000

\footnotetext{
${ }^{29}$ In 1994, Japan enacted a rapid increase of retirement age and a reduction of effective tax rates for workers close to retirement (Yashiro and Oshio, 1999). The model captures this rapid increase. In the United States, the retirement age started to increase around the year 2000, at a slower rate.

${ }^{30}$ Empirically, it has only been recently that many European countries have moved toward delaying the statutory retirement age and reducing the incentives for early retirement (e.g., Galasso, 2006, pp. 23-25), or to discussing proposals of such policy changes. This suggests that the model does not capture certain institutional frictions that delay adjustment along the retirement margin, or other motives for changes in the retirement age. For example, starting in the late 1960s and 1970s, early retirement provisions were introduced in many OECD countries in response to high levels of unemployment among middle-aged workers (see, e.g., Conde-Ruiz and Galasso, 2004). Our framework is silent about these developments.
} 


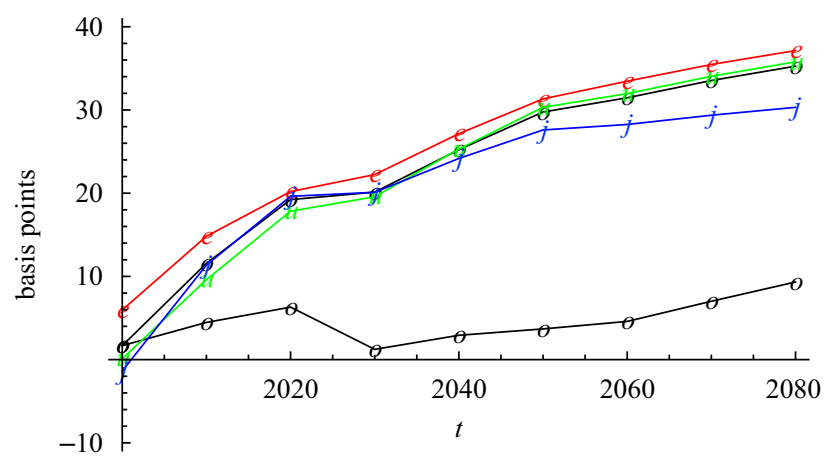

Fig. 10. Predicted annual per-capita output growth rates for the rich OECD economy (black, "o"), the rich European OECD economy (red, "e"), the United States (green, "u"), and Japan (blue, " $\mathrm{j}$ ") as deviations from the respective initial balanced-growth rates. The series at the bottom displays the growth deviation for the rich OECD economy if $\varrho_{t}$ is capped at its year-2000 value. (For interpretation of the references to color in this figure legend, the reader is referred to the web version of this article.)

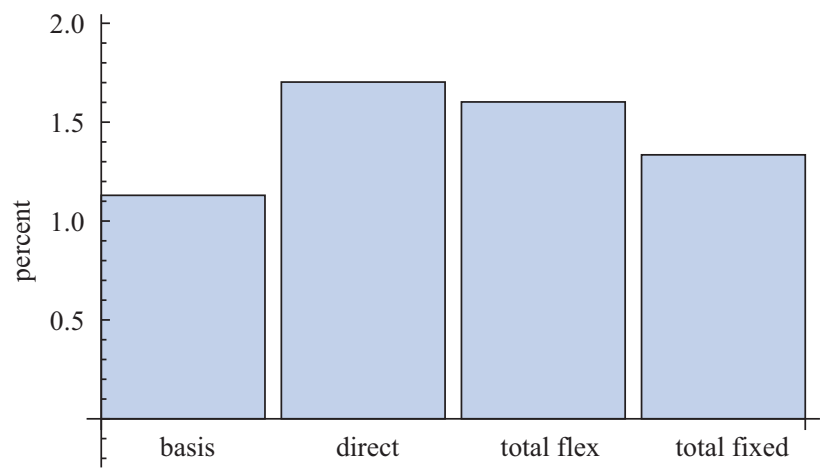

Fig. 11. Predicted annual per-capita balanced-growth rate (net) for the rich OECD economy, around the year 2000 (leftmost bar) and along the new balanced-growth path (middle and rightmost bars).

demographics. Annual growth accelerates by roughly four basis points per decade. By the year 2080, the growth rates have increased by 30-35 basis points. The growth accelerations in the rich OECD economy, the rich European OECD economy and the United States are very similar and slightly exceed the one in Japan. If the retirement age was capped at its level in the year 2000 (such that $\tau_{t}$ would rise steeply and $\sigma_{t}$ decline), per-capita growth would essentially remain stuck at its current level.

To understand the sources of these predicted growth effects, we compare the per-capita balanced-growth rate along the initial balanced-growth path subject to year-2000 demographics with the one along a new balanced-growth path subject to $p^{\star}=v^{\star}=1$. Recall from the discussion in Section 2.5 that the total growth effect of demographic change can be decomposed into a direct and an indirect, policy induced effect:

$$
\frac{\mathrm{d} \gamma_{H}((p, v), \kappa(p, v))}{\mathrm{d}(p, v)}=\frac{\partial \gamma_{H}((p, v), \kappa(p, v))}{\partial(p, v)}+\frac{\partial \gamma_{H}((p, v), \kappa(p, v))}{\partial \kappa} \frac{\partial \kappa(p, v)}{\partial(p, v)}
$$

The first term on the right-hand side includes the direct effect of demographic change on economic growth as described in Section 2.5. The second term includes the indirect effect working through induced policy adjustments as discussed in Section 3.

Fig. 11 illustrates the relative importance of these two effects. The leftmost bar (denoted by "basis") indicates the annual per-capita growth rate (net) along the balanced-growth path subject to year-2000 demographics. The other bars indicate the predicted growth rates along the new balanced-growth path subject to $p^{\star}$ and $v^{\star}$ under different assumptions about the adjustment of policy instruments. In particular, the bar denoted by "direct" indicates the new growth rate if only the direct effect is accounted for (corresponding to $\gamma_{H}\left(\left(p^{\star}, v^{\star}\right), \kappa\left(p_{2000}, v_{2000}\right)\right)$ ) and the bar denoted by "total flex" indicates the new growth rate if direct and indirect effects are accounted for (corresponding to $\gamma_{H}\left(\left(p^{*}, v^{*}\right), \kappa\left(p^{*}, v^{*}\right)\right)$ ). The rightmost bar denoted by "total fixed" indicates the new growth rate if direct and indirect effects are accounted for but the retirement age is held fixed at its year-2000 value.

Fig. 11 shows that the direct effect is positive, summing to 57 basis points of annual growth. In contrast, the indirect effect working through adjustments in policy is negative and amounts to roughly 10 basis points, due to higher transfers and later retirement and in spite of higher public investment. With a capped retirement age, the indirect growth effect would be much more negative ( 37 rather than 10 basis points), leaving a net growth increase of only 20 basis points. 


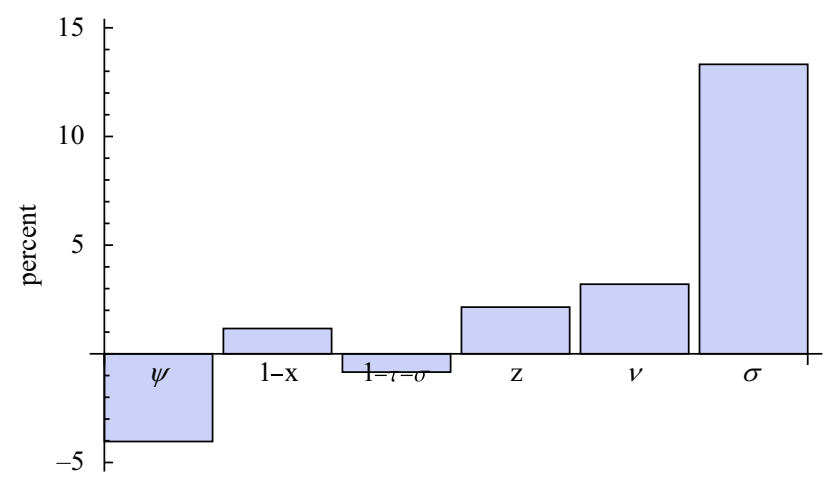

Fig. 12. Predicted change of the growth components for the rich OECD economy between the balanced-growth path around the year 2000 and the new balanced-growth path. The labels $\psi, 1-\chi, 1-\tau-\sigma, z, v$ and $\sigma$ refer to the components $\psi(\varrho)^{-\alpha \pi},(1-\chi)^{(1-\alpha) \pi},(1-\tau-\sigma)^{\alpha \pi}, z(\tau, \varrho)^{\alpha \pi}, v^{-\alpha \pi}$ and $\sigma^{(1-\alpha) \pi}$, respectively.

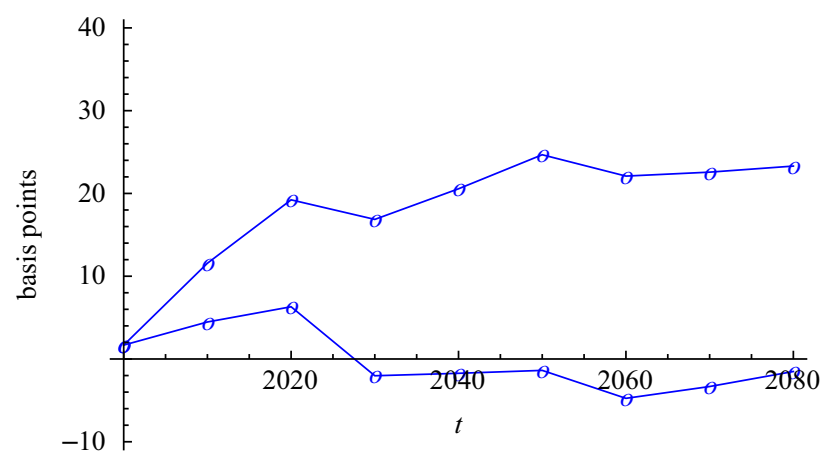

Fig. 13. Predicted annual per-capita output growth rate for the rich OECD economy as deviation from the initial balanced-growth rate if growth is exogenous and $\varepsilon=0.5$. The series at the bottom displays the growth deviation if $\varrho_{t}$ is capped at its year-2000 value.

We emphasize this last point: while in isolation, the increase of the retirement age works toward reducing growth, fixing the retirement age would not improve growth prospects; to the contrary, it would go hand in hand with an even stronger downward pressure on growth (more on this below).

Based on the expression for the growth rate in Eq. (5), Fig. 12 offers a different decomposition of the long-run growth implications of demographic ageing. According to (5), changes in the growth rate result due to changes in six components, namely

$$
\psi(\varrho)^{-\alpha \pi}, \quad(1-\chi)^{(1-\alpha) \pi}, \quad(1-\tau-\sigma)^{\alpha \pi}, \quad z(\tau, \varrho)^{\alpha \pi}, \quad v^{-\alpha \pi} \text { and } \sigma^{(1-\alpha) \pi},
$$

where $\pi \equiv \delta /(1-\alpha(1-\delta)) .{ }^{31}$ Fig. 12 shows that the components relating to labor supply (second component), the savings rate (fourth component), capital deepening (fifth component) and public investment (sixth component) contribute positively to the growth acceleration while the components relating to the labor supply of the elderly (first component) as well as the tax wedge (third component) contribute negatively. The component relating to the benefits of public investment, $\sigma^{(1-\alpha) \pi}$ (displayed in the rightmost bar), experiences the strongest acceleration, increasing by more than $13 \%$. Recall from our earlier discussion that with a fixed retirement age demographic ageing triggers a steep rise in social-security taxes and reduced public investment (see Fig. 6). We conclude that with a capped retirement age, the strong negative indirect growth effect discussed in the previous paragraph mainly is caused by crowding out of public investment.

In summary, the picture that emerges is only partly consistent with the view promoted by policy makers according to which the political process will implement measures to raise productivity in order to "outgrow" the burden imposed by demographic change. According to the model, demographic ageing indeed induces the political process to raise public investment in order to foster productivity growth. However, the main positive effects on growth arise directly, through capital deepening, a higher savings rate, and slightly increased labor supply and the net effect of endogenous policy on growth is negative. Viewed in isolation, the increase of the retirement age works toward reducing growth. However, when also considering the interaction with other policy instruments, flexibility along the retirement margin plays a positive role

\footnotetext{
31 Note that the decomposition in Fig. 12 compounds the direct and indirect effects distinguished in Fig. 11. For example, the component relating to the savings rate, $z(\tau, \varrho)^{\alpha \pi}$ (displayed in the fourth bar), captures both direct and policy-intermediated growth effects of demographic change as they work through the savings rate.
} 
for growth. For with a capped retirement age, social-security transfers would increase much more steeply, public investment would fall and the induced negative growth effects would be even stronger.

The central predictions of the model are robust to changes in the calibration. Modified values for the targeted balancedgrowth-path interest rate are mainly reflected in adjusted values for $\beta$ and $\delta$, leaving the simulation results largely unchanged. Reducing $\chi$ renders the predicted increase of retirement age less pronounced and more delayed. The effects on the decomposition of the long-run change in $\gamma_{H}$ are small but the growth cost of capping $\varrho$ is reduced. The most important parameter for calibration purposes is the capital share $\alpha$. Increasing $\alpha$ from 0.3 to 0.35 leaves the net long-run effect on $\gamma_{H}$ largely unchanged but amplifies the positive and negative contributions to this long-run change through the different channels discussed earlier. The predicted increase in retirement age is smaller if the capital share is high. If $\alpha$ is reduced to 0.25 , the retirement age steeply increases already before the year 2000. Starting from the high base value in the year 2000, the further increase of the retirement age does not depress growth as strongly as in the baseline simulation and the net effect of endogenous policy on long-run growth becomes positive. With a capped retirement age, the net effect of endogenous policy remains strongly negative.

The model predictions are also robust to replacing the endogenous-growth specification by one of exogenous growth. As discussed earlier, the equilibrium policy choices remain identical in such a variant of the model since the first-order conditions with respect to $\kappa_{t}$ are unchanged. ${ }^{32}$ To evaluate the robustness of the implied growth results, we simulate the model with the exogenous-growth specification introduced in Section 2.6. This model specification can be calibrated based on the same moment restrictions used previously, except for the one relating to the endogenous balanced-growth rate. This latter restriction (which does not apply any longer if $\gamma_{H}$ is determined by the exogenous $\gamma_{B_{1}}$ ) can now be dropped and the previously calibrated parameter in the production function for productivity growth imposed exogenously in the base year 2000. As a result, the numerical values for the model parameters $m, \beta, \delta$ and $\omega$ are given by the values calibrated previously and the parameter $B_{1}$ in the endogenous-growth specification is replaced by the sequence $\left\{B_{1, t}\right\}$ whose values grow at the exogenous rate $\gamma_{B_{1}}$. Based on this modified calibration, we can compute the balanced exogenous-growth values for the state variables in the base year, $H_{2000}$ and $q_{2000}$, and use the modified law of motion (6) to analyze the effect of the parameter $\varepsilon$ on the growth implications of the demographic transition.

As illustrated in Fig. 13, which corresponds to $\varepsilon=0.5$, the medium-term growth implications are very similar to those in the endogenous-growth specification. With endogenous growth, annual per-capita growth in the rich OECD economy is predicted to accelerate by $25-30$ basis points in the year 2050 and 30-35 basis points in the year 2080 (see Fig. 10). With exogenous growth and $\varepsilon=0.5$, in contrast, growth is predicted to accelerate by 25 basis points in the year 2050 before the economy begins to revert to its long-run growth rate of $\gamma_{H}=\left(\gamma_{B_{1}}\right)^{1 /(1-\delta)(1-\varepsilon)}$. Lower values for $\varepsilon$ imply a smaller maximal growth acceleration around the year 2050 and faster reversion thereafter. If $\varepsilon$ rises toward the limiting value of unity, the growth dynamics increasingly mimic those of the endogenous-growth specification. Finally, if the retirement age is restricted not to rise beyond its value in the year 2000, per-capita growth remains stuck at its level in the year 2000 , in parallel to the outcome with endogenous growth (see Fig. 13).

In conclusion, the specification of productivity growth in the model does not have a major bearing on the medium-term transition dynamics of the economy and no effect at all on the short-, medium- and long-run evolution of the policy instruments and the government budget shares in politico-economic equilibrium. ${ }^{33}$

\section{Concluding remarks}

We have presented a rich, yet tractable framework to analyze the impact of demographic ageing on economic growth. Building on a standard overlapping-generations model, our framework combines various channels discussed in the literature and referred to in the political debate. On the one hand, it captures the implications of rising longevity and falling fertility in general equilibrium, including adjustments in the savings rate, labor supply, factor prices and capital deepening. On the other hand, it captures responses by the political system, in particular adjustments of the size of the government budget and its composition between investment and transfer spending as well as changes in the retirement age.

Calibrated versions of the model predict that annual per-capita growth in rich OECD economies will increase by roughly 30-35 basis points during the 21st century, with the positive direct growth effects of demographic ageing partly being reversed by the consequences of endogenous policy responses. The model predictions support the view that rising longevity paired with falling fertility increases the GDP-share of social-security transfers, with negative implications for growth. However, they do not support the common view that rising social-security transfers crowd out productive public investment (as a share of GDP). Crowding out only results in an extreme scenario where the political process adjusts tax rates and the composition of government spending, but not the retirement age. In the more plausible scenario where the political process adjusts instruments along all three margins, both social-security transfers and public investment as a share of GDP rise, and the increase of the former is much more moderate than with a fixed retirement age. These results are robust to changes in the specification of the source of economic growth.

Throughout the paper, we have assumed that the government runs a balanced budget, excluding government deficits and debt. This assumption is not very restrictive. In our model, unlike in Bassetto and Sargent (2006) who assume

\footnotetext{
32 The latter result hinges on the assumption that households live for only two periods.

33 With exogenous growth, the long-run effect of the demographic transition on output is positive.
} 
commitment, public under-investment cannot be overcome by letting voters finance investment expenditures out of government debt. For lack of commitment implies that the economic equivalence of social-security and debt policies largely extends to the political sphere. ${ }^{34}$

We have also assumed that longevity and fertility are exogenous. While this assumption is useful for the purpose of studying the long-run effects of demographic ageing on growth, there are clearly potential feedback effects from government budgets to demographics, for example via investments in public health (see Hall and Jones, 2007). With endogenous fertility, the demographic structure would turn into an endogenous state variable, rendering an analytical solution of the policy game considered in the present paper infeasible. The magnitude of the feedback effects introduced by endogenous fertility would depend on assumptions, among others, about the direction of altruistic linkages between parents and children (Boldrin et al., 2005). We leave an analysis of these feedback effects for future research.

\section{Acknowledgements}

For comments, we thank the editor, two referees, Casper van Ewijk, Enrique Kawamura, George McCandless, Vincenzo Quadrini, Jaume Ventura, Fabrizio Zilibotti as well as conference and seminar participants at Banco Central de la República Argentina, CREI (Universidad Pompeu Fabra), EEA Annual Meeting, EPRU (University of Copenhagen), ESSIM, IIES (Stockholm University), Netspar, SED Annual Meeting, Study Center Gerzensee, and Universidad de San Andrés. Andreas Wälchli provided valuable research assistance.

\section{Appendix A. Production efficiency}

For generality, productivity growth is specified as $H_{t+1}=B_{1} H_{t}^{\varepsilon(1-\delta)} I_{t}^{\delta}$ with $0<\varepsilon \leq 1$. For $\varepsilon<1$, the model does not display endogenous growth.

Consider a path with constant $v$ and $p$ and let $y$ denote output per worker. Conditional on $H_{t}$ and aggregate labor supply, we have

$$
\ln \left(y_{t+i+1}\right) \simeq \alpha \ln \left(k_{t+i+1}\right)+\delta(1-\alpha) \sum_{j=0}^{i}(\varepsilon(1-\delta))^{j} \ln \left(I_{t+i-j}\right), \quad i \geq 0 .
$$

Starting from the investment policy $\left\{k_{t+i+1}, I_{t+i}\right\}_{i=0}^{\infty}$, consider a sequence of small reallocations of investment spending. This sequence involves, in each period $i$, a small change in public investment of $\Delta_{i}$ and a corresponding change in physical investment of $-\Delta_{i}$ (per worker in period $i$ ). If this policy change weakly increases output in all subsequent periods, then it amounts to a Pareto improvement and the initial allocation is production inefficient. Formally, the conditions for production inefficiency are given by

$$
d \ln \left(y_{t+i+1}\right)=-\alpha \frac{\Delta_{t+i}}{k_{t+i+1} v}+\delta(1-\alpha) \sum_{j=0}^{i}(\varepsilon(1-\delta))^{j} \frac{\Delta_{t+i-j}}{I_{t+i-j}}=-\alpha \frac{I_{t+i}}{k_{t+i+1} v} \varepsilon_{t+i}+\delta(1-\alpha) \sum_{j=0}^{i}(\varepsilon(1-\delta))^{j} \varepsilon_{t+i-j} \geq 0 \quad \text { for all } i \geq 0,
$$

where we define $\varepsilon_{t+i} \equiv \Delta_{t+i} / I_{t+i}$, and where at least one inequality must hold strictly. Since the initial allocation corresponds to a balanced-growth path, the recurrent term

$$
a \equiv-\alpha \frac{I_{t+i}}{k_{t+i+1} v}+\delta(1-\alpha)
$$

is time-invariant. The conditions for production inefficiency can therefore be summarized as

$$
\begin{aligned}
& a \varepsilon_{t} \geq 0 \\
& a \varepsilon_{t+i}+\delta(1-\alpha) \sum_{j=1}^{i}(\varepsilon(1-\delta))^{j} \varepsilon_{t+i-j} \geq 0 \quad \text { for all } i \geq 1,
\end{aligned}
$$

where at least one inequality must hold strictly.

Intuitively, the term $a$ (multiplied by the amount of physical investment) represents the effect of an infinitesimal reallocation from $k$ to $H$ investment on output in the subsequent period. To increase output in period $t+1, \varepsilon_{t}$ must have the same sign as $a$. To increase output in periods later than period $t+1$, the combined effect of the lagged changes in $k$ - and $H$-investment must be positive.

When $a>0$, capital is over accumulated in the initial allocation. As is apparent from the above conditions, one can generate a Pareto improvement in this case by reallocating resources from $k$ to $H$ (corresponding to $\varepsilon_{t+i}>0$ ). Over accumulation of capital is also present if $a=0$ and $\varepsilon(1-\delta)>0$, corresponding to the allocation in an economy without government intervention, but with markets for the provision of the "public investment." 35 In such a setting, savings is

\footnotetext{
${ }^{34}$ Gonzalez-Eiras and Niepelt (2010) analyze the economic and politico-economic equivalence of fiscal policies.

35 Boldrin and Montes (2005) and Docquier et al. (2007) characterize such an economy; they interpret public investment as public education.
} 
allocated across $H$ and $k$ investment in such a way that output in the subsequent period cannot be increased. However, if $\varepsilon(1-\delta)>0$, the level of productivity contributes to future productivity growth, and a slight reallocation from $k$ to $H$ investment therefore increases output in all later periods, as is apparent from the above conditions. The allocation satisfying $a=0$ is not Pareto optimal in this case because it does not properly account for the dynamic productivity externality.

When $a$ is negative and large in absolute value, the allocation again is production inefficient. In this case, a reallocation of resources from $H$ to $k$ accumulation (corresponding to $\varepsilon_{t+i}<0$ ) generates a Pareto improvement. For example, if $a=-1$, a sequence of $\varepsilon_{t+i}=\varepsilon<0$ for all $i \geq 0$ increases production in all future periods because the positive effect from additional physical investment, $a \varepsilon=-\varepsilon>0$, dominates the cumulative negative effect from reduced productivity growth, $\delta(1-\alpha) \sum_{j=1}^{i}$ $(\varepsilon(1-\delta))^{j} \varepsilon<\varepsilon$. To characterize the largest $a<0$ allowing for a persistent increase in output, we consider a sequence $\left\{\varepsilon_{t+i}^{\star}\right\}_{i=0}^{\infty}$ with $\varepsilon_{t}^{\star}<0$ where $\left\{\varepsilon_{t+i}^{\star}\right\}_{i=1}^{\infty}$ is recursively defined by the requirement that $\operatorname{dln}\left(y_{t+i}\right)=0$ for all $i \geq 2$. If such a sequence is bounded then production is inefficient. For $i \geq 1$, the terms of such a sequence satisfy $a \varepsilon_{t+i}^{\star}+\delta(1-\alpha) \sum_{j=1}^{i}(\varepsilon(1-\delta))^{j} \varepsilon_{t+i-j}^{\star}=0$. This implies

$$
\varepsilon_{t+1}^{\star}=\frac{\delta(1-\alpha)}{-a} \varepsilon(1-\delta) \varepsilon_{t}^{\star}
$$

and

$$
\begin{aligned}
\varepsilon_{t+i}^{\star} & =\frac{\delta(1-\alpha)}{-a} \sum_{j=1}^{i}(\varepsilon(1-\delta))^{j} \varepsilon_{t+i-j}^{\star}=\frac{\delta(1-\alpha)}{-a} \varepsilon(1-\delta) \varepsilon_{t+i-1}^{\star}+\frac{\delta(1-\alpha)}{-a} \sum_{j=2}^{i}(\varepsilon(1-\delta))^{j} \varepsilon_{t+i-j}^{\star} \\
& =\frac{\delta(1-\alpha)}{-a} \varepsilon(1-\delta) \varepsilon_{t+i-1}^{\star}+\frac{\delta(1-\alpha)}{-a} \varepsilon(1-\delta) \sum_{j=1}^{i-1}(\varepsilon(1-\delta))^{j} \varepsilon_{t+i-j-1}^{\star}=\frac{\delta(1-\alpha)}{-a} \varepsilon(1-\delta) \varepsilon_{t+i-1}^{\star}+\varepsilon(1-\delta) \varepsilon_{t+i-1}^{\star} \\
& =\varepsilon(1-\delta)\left(1-\frac{\delta(1-\alpha)}{a}\right) \varepsilon_{t+i-1}^{\star}, \quad i>1 .
\end{aligned}
$$

Boundedness of the sequence and thus production inefficiency requires $-1<\varepsilon(1-\delta)(1-\delta(1-\alpha) / a)<1$ which simplifies (due to $a<0)$ to the condition $a<-(1-\alpha) \varepsilon \delta(1-\delta) /(1-\varepsilon(1-\delta))$.

In conclusion, if $\varepsilon(1-\delta)>0$ (such that $a=0$ is not efficient), the criterion for production efficiency is given by $-(1-\alpha) \varepsilon \delta(1-\delta) /(1-\varepsilon(1-\delta)) \leq a<0$ for $a \equiv \delta(1-\alpha)-\alpha I / k v$. If the left inequality is violated, then the economy accumulates too much $H$; if the right inequality is violated, then the economy accumulates too much $k$.

In politico-economic equilibrium, $I_{t+i} / s_{t+i}=\sigma / z(1-\tau-\sigma)$ and the production efficiency criterion subject to $\varepsilon=1$ therefore reduces to

$$
1 \geq \frac{\alpha^{\prime} \sigma}{z(1-\tau-\sigma)}>\delta
$$

From the first-order condition for $\sigma$ tax rates in politico-economic equilibrium satisfy

$$
\frac{\alpha^{\prime} \sigma}{z(1-\tau-\sigma)}=\frac{\delta \alpha \beta p}{(1+\alpha \beta p) z}=\delta \frac{\alpha(1+\beta p)+(1-\alpha) \frac{\tau+\psi-1}{\psi}}{1+\alpha \beta p}<\delta,
$$

where the last inequality follows from $(\tau+\psi-1) / \psi<1$. We conclude that, in politico-economic equilibrium, the economy necessarily over accumulates $k$ relative to $H$.

\section{References}

Acemoglu, D., 2009. Introduction to Modern Economic Growth. Princeton University Press, Princeton.

Acemoglu, D., Johnson, S., 2007. Disease and development: the effect of life expectancy on economic growth. Journal of Political Economy 115 (6), 925-985.

Alesina, A., Rodrik, D., 1994. Distributive politics and economic growth. Quarterly Journal of Economics 109 (2), $465-490$.

Azzimonti, M., Sarte, P.-D., Soares, J., 2009. Distortionary taxes and public investment when government promises are not enforceable. Journal of Economic Dynamics and Control 33 (9), 1662-1681.

Barro, R.J., 1990. Government spending in a simple model of endogenous growth. Journal of Political Economy 98 (5), S103-S125.

Barro, R.J., Sala-i-Martin, X., 1995. Economic Growth. McGraw-Hill, New York.

Bassetto, M., Sargent, T.J., 2006. Politics and efficiency of separating capital and ordinary government budgets. Quarterly Journal of Economics 121 (4), $1167-1210$.

Bellettini, G., Berti Ceroni, C., 1999. Is social security really bad for growth? Review of Economic Dynamics 2, 796-819

Blankenau, W.F., Simpson, N.B., Tomljanovich, M., 2007. Public education expenditures, taxation, and growth: linking data to theory. American Economic Review Papers and Proceedings 97 (2), 393-397.

Bloom, D.E., Canning, D., Sevilla, J., 2003. The Demographic Dividend: A New Perspective on the Economic Consequences of Population Change. RAND, Santa Monica.

Boldrin, M., De Nardi, M., Jones, L.E., 2005. Fertility and Social Security. Research Department Staff Report 359. Federal Reserve Bank of Minneapolis. Boldrin, M., Montes, A., 2005. The intergenerational state: education and pensions. Review of Economic Studies 72, $651-664$.

Cass, D., 1972. On capital overaccumulation in the aggregative, neoclassical model of economic growth: a complete characterization. Journal of Economic Theory 4, 200-223.

Cervellati, M., Sunde, U., 2005. Human capital formation, life expectancy, and the process of development. American Economic Review 95 (5), $1653-1672$.

Conde-Ruiz, J.I., Galasso, V., 2004. The macroeconomics of early retirement. Journal of Public Economics 88 (9-10), 1849-1869.

Docquier, F., Paddison, O., Pestieau, P., 2007. Optimal accumulation in an endogenous growth setting with human capital. Journal of Economic Theory 134 (1), 361-378. 
Galasso, V., 2006. The Political Future of Social Security in Aging Societies. MIT Press, Cambridge, Massachusetts.

Galor, O., Weil, D.N., 1999. From Malthusian stagnation to modern growth. American Economic Review 89 (2), 150-154.

Glomm, G., Ravikumar, B., 1992. Public versus private investment in human capital: endogenous growth and income inequality. Journal of Political Economy 100 (4), 818-834.

Glomm, G., Ravikumar, B., 1997. Productive government expenditures and long-run growth. Journal of Economic Dynamics and Control 21 (1), $183-204$. Gonzalez-Eiras, M., Niepelt, D., 2005. Sustaining Social Security. Working Paper 1494, CESifo.

Gonzalez-Eiras, M., Niepelt, D., 2007. Population Ageing, Government Budgets, and Productivity Growth in Politico-economic Equilibrium. Discussion Paper 6581, CEPR.

Gonzalez-Eiras, M., Niepelt, D., 2008. The future of social security. Journal of Monetary Economics 55 (2), 197-218.

Gonzalez-Eiras, M., Niepelt, D., 2010. Economic and politico-economic equivalence of fiscal policies. Mimeo, Study Center Gerzensee.

Gradstein, M., Kaganovich, M., 2004. Aging population and education finance. Journal of Public Economics 88, 2469-2485.

Hall, R.E., Jones, C.I., 2007. The value of life and the rise in health spending. Quarterly Journal of Economics 122 (1), 39-72.

Hazan, M., 2009. Longevity and lifetime labor supply: evidence and implications. Econometrica 77 (6), 1829-1863.

Heathcote, J., Storesletten, K., Violante, G.L., 2010. The macroeconomic implications of rising wage inequality in the United States. Journal of Political Economy 118 (4), 681-722.

Jones, L.E., Manuelli, R.E., Rossi, P.E., 1993. Optimal taxation in models of endogenous growth. Journal of Political Economy 101 (3), $485-517$.

Krusell, P., Quadrini, V., Ríos-Rull, J.-V., 1997. Politico-economic equilibrium and economic growth. Journal of Economic Dynamics and Control 21 (1), 243-272.

Lindbeck, A., Weibull, J.W., 1987. Balanced-budget redistribution as the outcome of political competition. Public Choice 52, 273-297.

Perotti, R., 1993. Political equilibrium, income distribution, and growth. Review of Economic Studies 60, 755-776.

Persson, T., Tabellini, G., 1994. Is inequality harmful for growth? American Economic Review 84 (3), 600-621.

Persson, T., Tabellini, G., 2000. Political Economics. MIT Press, Cambridge, Massachusetts.

Poterba, J.M., 1997. Demographic structure and the political economy of public education. Journal of Policy Analysis and Management 16 (1), 48-66.

Rangel, A., 2003. Forward and backward intergenerational goods: why is social security good for the environment? American Economic Review 93 (3), 813-834.

Rebelo, S., 1991. Long-run policy analysis and long-run growth. Journal of Political Economy 99 (3), 500-521.

Soares, R.R., 2005. Mortality reductions, educational attainment, and fertility choice. American Economic Review 95 (3), $580-601$.

Tanzi, V., Schuknecht, L., 2000. Public Spending in the 20th Century: A Global Perspective. Cambridge University Press, Cambridge, United Kingdom.

Yashiro, N., Oshio, T., 1999. Social security and retirement in Japan. In: Gruber, J., Wise, D.A. (Eds.), Social Security and Retirement Around the World. University of Chicago Press, Chicago, pp. 239-267 (Chapter 6). 